Canadian

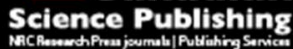

Canadian Geotechnical Journal Revue canadienne de géotechnique

\title{
Frac Sand Crushing Characteristics and Morphology Changes under High Compressive Stress and Implications for Sand Pack Permeability
}

\begin{tabular}{|r|l|}
\hline Journal: & Canadian Geotechnical Journal \\
\hline Manuscript ID & cgj-2016-0045.R1 \\
\hline Manuscript Type: & Article \\
\hline Date Submitted by the Author: & 27-Apr-2016 \\
\hline Complete List of Authors: & $\begin{array}{l}\text { Zheng, Wenbo; University of British Columbia, School of Engineering } \\
\text { Tannant, Dwayne; University of British Columbia, School of Engineering }\end{array}$ \\
\hline Keyword: & Frac sand; sand crushing; grain shape; sand pack permeability \\
\hline \multicolumn{2}{|l}{} \\
\hline
\end{tabular}

\section{SCHOLARONE"}

Manuscripts 


\section{Frac Sand Crushing Characteristics and Morphology Changes under High Compressive Stress and Implications for Sand Pack Permeability}

Wenbo Zheng and Dwayne Tannant

Wenbo Zheng. School of Engineering, University of British Columbia, Kelowna, BC V1V 1V7, Canada. (e-mail: wbzheng@alumni.ubc.ca)

Dwayne Tannant. School of Engineering, University of British Columbia, Kelowna, BC V1V 1V7, Canada. (e-mail: dwayne.tannant@ubc.ca)

*Corresponding author: Wenbo Zheng. School of Engineering, University of British Columbia, Kelowna, BC V1V 1V7, Canada. Phone number: 1.250.899.5902. E-mail: wbzheng@alumni.ubc.ca 
ABSTRACT: Sand consisting of round quartz grains is widely used as a proppant during

2 hydraulic fracturing to produce natural gas from tight shale formations. This paper presents

3 results from sand characterization and crushing tests on Jordan Formation frac sand. It includes

4 an assessment of grain size reduction, changes in particle shape, and reduction in void ratio. It

5 also examines the implications for permeability reduction through a sand pack caused by the

6 closure stress on a hydraulic fracture. The sand from two size ranges $(0.6$ to $0.71 \mathrm{~mm}$ and 0.5 to

$7 \quad 0.6 \mathrm{~mm}$ ) was tested dry under applied compressive stresses of up to $40 \mathrm{MPa}$ in a crushing cup.

8 The overall sand pack stress-strain response becomes softer as grains are crushed. The particle

9 shape shifts from nearly spherical grains to diametrically split grains and then to small elongated

10 and angular fragments for the smaller particle sizes. The permeability of the sand pack reduces

11 by more than $40 \%$ at a $20 \mathrm{MPa}$ stress, which is mainly caused by a decrease in void ratio due to

12 compaction. The permeability reduces by over $70 \%$ at a $40 \mathrm{MPa}$ stress, which is primarily

13 caused by void ratio decrease, reduction in particle size, and a shift away from spherical particle

14 shapes. Compared to the ISO 13503-2 standard where only the sand crushing percentage after

15 crushing tests is measured, this paper demonstrates that more information can be extracted from

16 sand crushing tests and that sand pack permeability can be assessed to optimize frac sand

17 selection. A sand with a larger size range has a higher crushing percentage but is more permeable

18 compared to a sand with a smaller size range. This further indicates that frac sand selection based

19 only on sand crushing percentage is not sufficient to achieve a better sand pack permeability.

20 Keywords: Frac sand; sand crushing; grain shape; sand pack permeability 


\section{Introduction}

24 Frac sand is widely used as a proppant for hydraulic fractures used to increase the 25 recovery rate of hydrocarbons in oil and gas industry. The North American market consumes

26 more than $80 \%$ of the world's supply of frac sand and nearly $50 \%$ of this frac sand is mined in

27 Wisconsin (Benson and Wilson 2015). Typically hydraulic fractures in tight shale formations are

28 created several kilometres beneath the ground surface. Fracturing fluids transport proppants to

29 newly-created fractures and a proppant pack is then formed within the fractures. After hydraulic

30 fracturing, stress from the surrounding formations will act on the hydraulic fractures. This stress

31 is called the closure stress and it tends to reduce the aperture of fractures. A proppant pack is

32 designed to resist the closure stress and prop open fractures, and act as paths for oil and gas to

33 flow. The closure stress for different shale formations varies but is typically larger than $30 \mathrm{MPa}$,

34 e.g. $60 \mathrm{MPa}$ to $80 \mathrm{MPa}$ for Haynesville Shale, less than $40 \mathrm{MPa}$ for Fayetteville Shale, and

35 roughly $40 \mathrm{MPa}$ for the Montney Shale (Song and Hareland 2012). The high closure stress acting

36 on proppants within the hydraulic fractures often crushes proppant grains into smaller fragments

37 (Palisch et al. 2009). For example, crushed sand was observed in flow back tests from the

38 Montney Formation under a closure stress of $42.3 \mathrm{MPa}$ (Romanson et al. 2010). Proppant

39 crushing allows the hydraulic fracture to close thus reducing the fracture aperture. Furthermore,

40 the presence of small fragments of crushed sand decreases the permeability or hydraulic

41 conductivity of the proppant pack because they can block natural gas flow paths. Coulter et al.

42 (1972) and Lacy et al. (1997) both found that 5\% fines can cause an over 50\% reduction in the

43 proppant pack conductivity, which is defined as the proppant pack permeability times the

44 fracture aperture. A study for the Bakken Formation showed that the permeability of a ceramic 45 proppant pack was five times higher than that of Ottawa sand under approximately $50 \mathrm{MPa}$ 
46 closure stress. The higher permeability was attributed to the higher crushing resistance of the

47 ceramic proppants (Kurz et al. 2013).

Sand crushing was noted by Terzaghi and Peck (1948) in one-dimensional compression

49 tests on sands subjected to $95.6 \mathrm{MPa}$. Many studies have quantified a change in the grain size

50 distribution due to crushing (Lade et al. 1996; Zhang and Baudet 2013) and its effect on

51 macroscopic properties of the sand, e.g., density, void ratio, friction angle, critical state line, etc.

52 (Chuhan et al. 2002; Luzzani and Coop 2002; Coop 2004; Ghafghazi et al. 2014). A single-

53 particle crushing test was used to measure the crushing characteristics and strength statistics of

54 quartz, orthoclase, and plagioclase sand grains (Nakata et al. 1999). Parab et al. (2014) used x-

55 ray computed tomography to observe sand crushing under static loading. A sand grain was

56 observed to break into several particles followed by cracking in a second grain once the first

57 grain was completely pulverized. Sand crushing changes the shape of sand grains, which, in

58 return, affects the mechanical behaviour of sand. The term 'morphology' of sand is used to

59 describe the external size and shape of the grains and fragments (Blott and Pye 2008). The

60 morphology of sand grains affects its density, void ratio, shearing response, stiffness and

61 coefficient of lateral stress (Yimsiri and Soga 1999; Latham et al. 2002; Cho et al. 2006; Guo

62 and Stolle 2006; Tsomokos and Georgiannou 2010). Angular grains have lower crushing

63 strength compared to round grains (Cheng et al. 2004; Gaurav et al. 2012). A numerical study

64 (Ueda et al. 2013) showed that cleavage destruction, bending fracture, and edge abrasion were

65 observed in circular or elliptical, elongated, and angular particles respectively. Sand crushing and

66 the change in shape and grain size distribution reduces the permeability of sand by decreasing

67 the internal pore space and altering the pore shape. Sand with irregular-shaped grains was shown

68 to be $1.6 \sim 1.8$ times less permeable than sand with round grains under gravity packing in a 
69 numerical study using finite element flow simulation through internal pore structures (Garcia et 70 al. 2009).

71 The oil and gas industry uses the ISO 13503-2 standard (2006) for testing the crushing 72 characteristic of sand and to compare and select frac sand for hydraulic fracturing. However, this 73 standard test only measures the percent of fines generated due to crushing under a specified 74 compressive stress. The frac sand is not selected on the basis of other sand properties such as the 75 stress-strain response, grain size gradation, and changes in sand grain shape as they are crushed.

76 These properties are typically not measured during the standard crush test and are thus poorly 77 understood. Furthermore, the impact of these factors on changes in the sand pack permeability is 78 largely unknown. To address these issues, this paper uses an experimental approach to 79 characterize the crushing characteristics and morphology change of frac sand from the Jordan 80 Formation in Wisconsin, a popular source for frac sand with high roundness and good crushing 81 resistance. The permeability reduction due to sand crushing is also interpreted. The results

82 improve our understanding of the behaviour of Jordan frac sand under compression. This paper

83 also demonstrates that more information can be extracted from the crushing test than is currently 84 done, which can be used to optimize frac sand design to achieve a better sand pack permeability 85 under field conditions.

\section{Jordan Formation Frac Sand}

\section{Geology description}

Sand used as a proppant in hydraulic fractures usually consists of highly pure quartz

89 grains with ideal roundness and crushing resistance. In Wisconsin and Minnesota, frac sand is

90 mined from four sandstone formations, namely the Middle and Upper Ordovician St. Peter

91 Formation, the Upper Cambrian and Lower Ordovician Jordan Formation, the Cambrian Upper 
92 Wonewoc Formation, and the Cambrian Mount Simon Formation. Figure 1 shows the

93 distribution of these sandstone formations and the active/proposed frac sand mines and

94 processing plants in Wisconsin. Among the four source formations, the Van Oser Member of the

95 Jordan Formation has the highest percentage of desirable grain sizes (i.e., over $45 \%$ larger than

96 mesh 40 by weight) and the lowest percentage of less desirable grain sizes (i.e., about 5\%

97 smaller than mesh 100 by weight) for hydraulic fracturing (Ostrom 1971).

98 The Jordan Formation is a marine sandstone that was deposited 500 million years ago.

99 Outcrops of this formation were first described in streams and quarries near Jordan City,

100 Minnesota by Winchell (1874). This sandstone was extensively studied by Runkel et al. (1994a,

101 1994b, 2000, 2012). Chemical weathering is believed to have induced selective diagenetic

102 leaching of plagioclase grains and other unstable minerals from the source rock for the sand that

103 was eventually deposited. This created a mineralogically mature source area dominated by quartz

104 grains (Odom's 1975, 1978). The sand was then carried by wind and rivers to shorelines located

105 in Wisconsin, Minnesota and Northern Iowa. Abrasion in marine conditions as well as wind

106 abrasion jointly created the textural maturity of the sand.

107 Two quartzose sandstone members are included in the Jordan Formation. The uppermost

108 Van Oser Member consists of fine to medium-grained, cross-stratified, well-sorted, quartzose

109 sandstone with 9 to $15 \mathrm{~m}$ thickness. The underlying Norwalk Member is a fine-grained,

110 moderately sorted feldspathic sandstone with a thickness 15 to $18 \mathrm{~m}$ (Mudrey et al. 1987). The

111 Van Oser is interpreted as a higher energy, marine intertidal sand while the Norwalk is as a low-

112 energy, below wave base sand (Brown 2012).

113 The Jordan Formation is poorly cemented but does have some cement-like calcite, which

114 may locally create tightly cemented aggregates so blasting is sometimes used to make the 
115 sandstone more amenable to excavation. After excavation, the sandstone is crushed to recover

116 the sand grains, which are then washed to remove fine particles such as silts and clays. The sand

117 is then sent to a dryer and screening plant to sort the sand into desired sizes for hydraulic

118 fracturing (Wisconsin Department of Natural Resources 2012).

\section{Grain size and microstructure}

120 The Jordan Formation frac sand used in this paper was washed in a processing plant near

121 Plum City, Wisconsin, and then shipped to a drying and screening plant near Seven Persons, 122 Alberta, for final processing. One of the most popular sizes of frac sand, mesh 20/40 as shown in 123 Fig. 2, is used for this study. Mesh 20 and 40 is equivalent to $0.85 \mathrm{~mm}$ and $0.425 \mathrm{~mm}$ 124 respectively. A mesh $20 / 40$ sand means more than $90 \%$ of sand grain by weight is retained 125 between $0.85 \mathrm{~mm}$ and $0.425 \mathrm{~mm}$. A visual examination of the sand shows that most grains 126 appear round and clean although some of the grain surfaces have a yellowish tone that may 127 indicate a thin oxide coating. There are also occasional grains consisting of an agglomeration of 128 smaller particles.

The grain size distribution for the 20/40 mesh size sand as received from the supplier was

130 determined following the ASTM D6913 (2009) sieving standard. A 100 g representative sample 131 of the sand under an air-dried condition was obtained and sieved with a $200 \mathrm{~mm}$ diameter metric 132 sieve set on a shaker for 20 minutes. Table 1 shows the size distribution obtained by sieving. As 133 expected for a $20 / 40$ mesh sand, $80 \%$ of the sand grains by weight fall between sieve sizes of $134 \quad 0.50 \mathrm{~mm}$ and $0.71 \mathrm{~mm}$.

135 A Tescan Mira3 XMU field emission Scanning Electron Microscope (SEM) with $2 \mathrm{~nm}$ 136 back-scattered electron resolution at $30 \mathrm{kV}$ was used to investigate the microstructure of the 137 natural and fractured sand grains. 
139 was used to obtain the textures of natural grain surfaces and new fracture faces. The collected

140 was sieved to four different sizes and then examines in a SEM. A sputtercoater was used to 141 deposit a $10 \mathrm{~nm}$ thickness of a platinum-palladium alloy on the sand grains or particles to form a 142 conductive surface.

143 As shown in Fig. 3, most sand grains from the $0.425 \mathrm{~mm}$ sieve remained unbroken 144 although a few grains showed signs of abrasions or diametrical failures. For the $0.315 \mathrm{~mm}$ sieve, 145 grains split in the middle were common and some cracks were present. Grains from the $0.16 \mathrm{~mm}$ 146 sieve consisted of angular elongated fragments of sand grains. The smallest size fraction 147 (0.08 mm sieve) consisted of more elongated fragments. New fracture faces and grain surfaces 148 are easily distinguished from each other by their texture (smooth or rough).

\section{Crushing Characteristics of Frac Sand}

150 Sand crushing resistance and grain breakage characteristics affect the stress-strain 151 response of sand and grain size degradation under compression, which is directly linked to sand 152 pack permeability. It is also widely acknowledged that sand grains with different sizes might 153 have different crushing strength (Nakata et al. 2001). To design a sand pack with higher crushing 154 resistance and permeability, it is important to understand the crushing strength of different sand 155 sizes and then to optimize the grain size distribution of the sand pack for different closure 156 stresses.

157 One-dimensional compression tests were used to investigate the frac sand crushing 158 characteristics. The crushing tests presented in this paper were performed on sand grains retained 159 on $0.5 \mathrm{~mm}$ and $0.6 \mathrm{~mm}$ sieves respectively, because these are the major size components of mesh $16020 / 40$ sand, the most commonly used size range for hydraulic fracturing. Ongoing research is 
161 studying the crushing characteristics of other grain sizes including $0.71 \mathrm{~mm}, 0.425 \mathrm{~mm}$ and

$1620.355 \mathrm{~mm}$, and sand mixtures with different grain sizes but this work is beyond the scope of this

163 paper. It should also be noted that the crushing tests were performed on dry sand without

164 considering fluids or pore pressure. The sand used for the crushing test that came from a $0.5 \mathrm{~mm}$

165 sieve is termed as G500 sand, and G600 for sand from a $0.6 \mathrm{~mm}$ sieve.

\section{Test apparatus and procedure}

This test involves placing sand into a steel cup and then applying a compressive stress to

168 the top of the sand with a steel loading piston as seen in Fig. 4. The testing apparatus were 169 smaller than that used for the ISO 13503-2 standard to facilitate good acoustic emission 170 monitoring while keeping the thickness of the sand in the cup similar to that in a real hydraulic

171 fracture. The cup has a $25.4 \mathrm{~mm}$ inner diameter, $50.8 \mathrm{~mm}$ outer diameter, and is $70.28 \mathrm{~mm}$ deep.

172 The loading piston is $25.4 \mathrm{~mm}$ in diameter and $80 \mathrm{~mm}$ long. A compression force was vertically

173 applied to the piston using a Instron $3385 \mathrm{H}$ testing machine with a load capacity of $250 \mathrm{kN}$, load

174 measurement accuracy of $0.5 \%$ down to $2.5 \mathrm{kN}$, and strain measurement accuracy of $0.5 \%$. The

175 loading rate was set to $0.1 \mathrm{~mm} / \mathrm{min}$ to maintain a stress increase at less than $0.5 \mathrm{MPa} / \mathrm{s}$. The

176 stress applied to the sand pack in the cup and the resulting strain was measured at a rate of

$177100 \mathrm{~Hz}$ during each test.

178 A $27 \mathrm{~mm}$ diameter piezoelectric sensor with a resonant frequency of $6.3 \mathrm{kHz}$ was 179 attached to the outside of the steel cup to record the sound created by sand grain fractures 180 throughout the compression test. The sound from the crushing sand creates a voltage in the 181 piezoelectric sensor, which was amplified and recorded at a rate of $25 \mathrm{kHz}$ using a National 182 Instruments USB-6210 data logger. A Fast Fourier transform was performed on the acoustic 183 emission (AE) data recorded during the crushing tests. The waveforms detected by the 
184 piezoelectric sensors were filtered to remove frequencies under $200 \mathrm{~Hz}$, which were found to be

185 associated with background noise. The grain breaking events have frequencies ranging between $186400 \mathrm{~Hz}$ to $8000 \mathrm{~Hz}$.

187 For each crushing test, $10 \pm 0.1 \mathrm{~g}$ of sand was placed into the cup. The cup was placed 188 onto a vibration table to level the sand surface and to achieve an approximately constant initial 189 void ratio. The compressive stress applied to the sand in the crushing cup was up to $40 \mathrm{MPa}$ to 190 mimic the typical closure stresses in hydraulic fractures. The height of the sand in the steel cup 191 was measured before the start of each crush test. These data were used to calculate the initial 192 void ratio in the sand pack assuming that the quartz sand grains have a density of $2.65 \mathrm{~g} / \mathrm{cm}^{3}$.

193 The tests were repeated five times to evaluate inherent variability in the test data and to 194 obtain a sufficient mass of sand for subsequent sieving. After each set of five tests, a sieve 195 analysis was performed to determine the grain size distribution and the morphological properties 196 of the crushed sand grains were analyzed.

\section{Test results}

198 After a compression test, the piston was removed from the cup and the sand grains inside 199 the cup were observed with a microscope. A typical example of sand crushing due to 200 compression is shown in Fig. 5. Diametrical failures in which a grain splits into two halves, can

201 be seen at locations 1 to 3 . At location 4 and 5, the split grains were further broken into many 202 pieces of finer fragments. The white coloured particles of sand are fresh fines generated due to 203 crushing.

204 The grain size distributions under applied stress levels of 10, 20, 30, and $40 \mathrm{MPa}$ were 205 obtained to understand the grain size variation with stress as shown in Fig. 6. The results reveal 206 that sand crushing becomes significant once the compressive stress exceeds approximately 
$20730 \mathrm{MPa}$. For crushing tests on G600 sand, at maximum compressive stresses of 30 and $40 \mathrm{MPa}$, $20814 \%$ and $29 \%$ of the original sand were respectively crushed to finer sizes and $2.7 \%$ and $11 \%$ of 209 sand by weight respectively passed through a $0.355 \mathrm{~mm}$ sieve size. For crushing tests on G500 210 sand under compressive stresses of $30 \mathrm{MPa}$ and $40 \mathrm{MPa}, 10 \%$ and $25 \%$ of the original sand were 211 respectively crushed to finer size and $3.2 \%$ and $12 \%$ of sand by weight respectively passed 212 through a $0.355 \mathrm{~mm}$ sieve. This indicates that sand particles in a size range of 0.355 to $0.425 \mathrm{~mm}$ 213 were further crushed into even smaller fragments. Note that G600 sand shows a lower crushing 214 resistance compared to G500 sand because more grains are crushed at a given stress level.

215 The stress-strain responses from five crush tests on G500 sand are shown in Fig. 7. From 2160 to $10 \mathrm{MPa}$, the stress carried by the G500 sand pack increased smoothly as the grains were 217 compacted. There is a drop in the vertical stress around $12.6 \pm 1.6 \mathrm{MPa}$ (mean \pm standard 218 deviation using 5 tests) as shown in the stress-strain curves due to one or more grains breaking as 219 verified with AE detection. This is similar to the one dimensional compression experiments by 220 Hagerty et al. (1993) that indicated sand crushing began at an applied stress as low as $15 \mathrm{MPa}$. 221 The stress increased with multiple small stress drops as further grains were broken especially 222 when the stress exceeded $10 \mathrm{MPa}$, resulting in a zigzag shape for the stress-strain curve. It is also 223 noted that the slope of the stress-strain curve became shallower and each drop in stress is less 224 significant after $30 \mathrm{MPa}$ compared to stresses from 10 to $30 \mathrm{MPa}$. The average one-dimensional 225 constrained modulus of the sand pack at stresses between 15 and $25 \mathrm{MPa}$ is $485 \pm 27 \mathrm{MPa}$ while 226 that between 32 and $38 \mathrm{MPa}$ is $250 \pm 31 \mathrm{MPa}$. The decrease in the constrained modulus may be 227 explained by the generation of smaller and more tabular sand fragments at compressive stresses 228 in the range of 30 to $40 \mathrm{MPa}$ as verified by the grain size distributions and the microscopic 
229 morphology of the sand grains. The sand pack exhibits a less stiff response when these fragments

230 are present and significant crushing of sand is occurring.

231 The positive values of the filtered AE voltage for Test 1 of G500 sand loaded up to

$23240 \mathrm{MPa}$ compressive stress are presented in Fig. 8. The voltage spikes and stress drops are

233 coincident with each other. For example, a voltage spike larger than $3 \mathrm{~V}$ occurs at approximately

234 11.5 $\mathrm{MPa}$ corresponding to the first large drop in stress. This shows that the stress drop was

235 caused by grain breaking. The larger voltage spikes $(>1 \mathrm{~V})$ occur between compressive stresses

236 of 10 and $30 \mathrm{MPa}$. The voltage spikes occurring when the stress was between 30 and $40 \mathrm{MPa}$ are

237 typically smaller than $1 \mathrm{~V}$. The smaller AE signals that occur at higher stress levels might be

238 explained by the evolving nature of the grain size distribution under different stresses. As shown

239 in Fig. 6, only 3.5\% of G500 sand was crushed to finer particles under a compressive stress of

$24020 \mathrm{MPa}$. Most of these fragments remained on sieve sizes of $0.355 \mathrm{~mm}$ and $0.425 \mathrm{~mm}$, indicating

241 that the initial sand crushing was dominated by grains being split into two halves. The creation of

242 small sand particles as the compressive stress increased may increase the number of contact

243 points among the grains or fragments and thus more evenly distribute the contact forces. This in

244 turn may result in smaller energy releases during subsequent crushing and thus lower voltage

245 spikes.

246 For G600 sand, the stress applied to the sand increased smoothly and then experienced its

247 first drop at a compressive stress around 9.6 $\mathrm{MPa}$ ( \pm std. dev. $1.7 \mathrm{MPa}$ using 5 tests) as seen in

248 Fig. 9, which is slightly lower compared with G500 sand (12.6 $\pm 1.6 \mathrm{MPa})$. This may be

249 explained by larger size grains having a lower strength than the smaller size grains since more

250 defects are likely in a bigger sand grain. The average one-dimensional constrained modulus at

251 stresses between 15 and $25 \mathrm{MPa}$ is $467 \pm 44 \mathrm{MPa}$ while that between 32 and $38 \mathrm{MPa}$ is $221 \pm$ 
$25231 \mathrm{MPa}$. The average one-dimensional constrained modulus of G600 sand under lower stress 253 levels (15 to $25 \mathrm{MPa}$ ) is similar to G500 sand. This may be because the degree of sand crushing 254 is similar for the two sand sizes at this stress level. At a higher stress the sand pack consisting of 255 the larger G600 sand grains had a lower modulus than G500 sand. The compressive stress and 256 AE voltage versus time for Test 2 of G600 sand are presented in Fig. 10. A spike with voltage 257 larger than $2.1 \mathrm{~V}$ occurs at approximately $9 \mathrm{MPa}$ when the first large stress drop occurred. This 258 further shows that the stress drop was caused by grain breaking. Voltage spikes that are larger 259 than $1 \mathrm{~V}$ occur between compressive stresses of 9 and $25 \mathrm{MPa}$, while voltage amplitudes at 260 stresses between 25 to $40 \mathrm{MPa}$ were typically lower than $1 \mathrm{~V}$.

261 An attempt was made to count the number of individual AE events that occurred during 262 each crush test. The approach suggested by Zhao et al. (2013) was used for this purpose. AE 263 readings with a voltage higher than a threshold of $0.02 \mathrm{~V}$ were first determined and then those 264 readings which occurred within an event duration $0.03 \mathrm{~s}$ were counted as a single crushing event.

265 The AE voltage and the AE event count are plotted versus the strain in Figs. 8 and 10 for tests on 266 G500 and G600 sand. For the G500 sand, the number of AE events increased slowly to 267 approximately 300 at $25 \mathrm{MPa}$ and then more quickly to just over 1000 events at $40 \mathrm{MPa}$. For 268 G600 sand, the number of AE events increased slowly to around 360 at $25 \mathrm{MPa}$ and then 269 dramatically to 1450 at $40 \mathrm{MPa}$. The $\mathrm{AE}$ event rate is defined as the number of $\mathrm{AE}$ events per 270 every $2 \%$ vertical strain of the sand pack. As shown in Figs. 8 and 10, the AE event rate of G500 271 sand increases from about 50 events/2\% strain at $10 \mathrm{MPa}$ to about 200 events/2\% strain at 272 stresses between 25 to $40 \mathrm{MPa}$. For G600 sand, the AE event rate increases from about 50 273 events $/ 2 \%$ strain near $10 \mathrm{MPa}$ to 300 events/2\% strain at stresses between 25 to $40 \mathrm{MPa}$. 
274 Consistent with the grain size data, the number of AE events and the AE event rate both indicate

275 that more grains of G600 sand were broken than G500 sand under the same stress levels.

276 To compare the crushing strength of the Jordan Formation frac sand with other kinds of

277 sand, the Hardin relative breakage $\left(B_{r}\right)$ of G500 and G600 sand was calculated based on the grain

278 size distribution (Hardin 1985). The values for $B_{r}$ are plotted in Fig. 11, where they are compared

279 with data from Coop and Lee (1993) for well sorted the Dogs Bay sand $\left(D_{50}=0.28 \mathrm{~mm}\right)$ and the

280 Ham River sand $\left(D_{50}=0.227 \mathrm{~mm}\right)$, and from Vilhar et al. (2013) for Bostanj silty sand $\left(D_{50}=\right.$

$2810.11 \mathrm{~mm})$. The data from the one-dimensional tests have been plotted by assuming $\phi^{\prime}=34^{\circ}$ and

$282 K_{0}=1-\sin \phi^{\prime}$ for calculating the mean stress $\left(p^{\prime}\right)$. The G500 has slightly lower values of $B_{r}$ than

283 the G600 under the same stress level. The G600 and G500 sand exhibit much lower breakage

284 than the Dogs Bay sand and the Ham River sand, while the sand has similar breakage to the

285 Bostanj silty sand. It should be noted that G600 and G500 have a much higher $\mathrm{D}_{50}$ than the

286 Bostanj silty sand, which implies the crushing resistance of the Jordan Formation sand is higher 287 than the Bostanj silty sand assuming the crushing strength increases with the decrease of the 288 grain size. Based on the shift in the gradient of the stress-strain curves in Figs. 7 and 9 and the 289 void ratio versus stress curve in Fig. 12. G500 and G600 has a yield point at around 27.8 MPa 290 and 24.8 MPa respectively. These are higher than yield stress of a silica sand (11.6 MPa for size $2910.61 \sim 0.71 \mathrm{~mm} ; 16.9 \mathrm{MPa}$ for size $0.25 \sim 0.3 \mathrm{~mm}$ ) and close to that of glass ballotini (26.5 MPa for 292 size $0.85 \sim 1.0 \mathrm{~mm}$ ) as reported by Nakata et al. (2001) for one-dimensional compression test 293 results.

\section{Morphology Change of Sand Grains Due to Crushing}

Sand crushing changes the grain shape and size, which affects the mechanical behaviour

296 and permeability of the sand pack. A comprehensive analysis using images of the grains or 
297 fragments captured by a microscope was conducted to characterise sand particle size and shape

298 before and after the crushing tests. An optical Zeiss Stereo Discovery.V8 microscope with a 299 build-in camera (AxioCam ICC1) was used to examine the sand grains. The microscope 300 objective lens has a magnification from $25 \mathrm{x}$ to $200 \mathrm{x}$. The sand was placed into a plastic petri dish 301 with a black bottom while the lighting was from above. Grains were separated carefully to avoid 302 grain overlap or touching before images were captured. A calibration slide was used to calibrate 303 the scale of the field of view. ImageJ software (Schneider et al. 2012) was used to perform a morphology analysis of the grains. ImageJ is a Java-based image processing program with user-defined plugins and recordable macros. Measurements for each individual particle were evaluated from its image and 307 results were filtered by particle size and circularity. Several 2D particle shape descriptors are used. These include the $2 \mathrm{D}$ area $(A)$ and perimeter $(P)$ of each grain. Sphericity $(S)$ and 309 roundness $(R)$ of the grain make use of the calculated area and perimeter and are defined in 310 Equations 1 and 2 and have a maximum value of 1 for circles. For a square, $R=0.785$ while $S=$

311 1. The major axis was found for the best fit ellipse with the same area, orientation, and centroid 312 to the original shape as shown in Fig. 13. The maximum Feret diameter (MaxFeret) is the 313 maximum distance between two parallel tangents touching the outline of a grain. The minimum 314 Feret diameter (MinFeret) corresponds to the minimum distance which is similar to a caliper 315 diameter. The ratio of MinFeret and MaxFeret is the aspect ratio $(A R)$. The roughness parameter $316 R$ used in this paper describes overall roughness while that defined by Krumbein and Sloss 317 (1963) is more focused on local sharpness using a few sharpest corners, which is a scale318 dependent parameter. The meaning of $R$ and $S$ values can be appreciated by reference to Fig. 14, 319 which is a plot of representative quartz particles retained on sieve sizes from $0.08 \mathrm{~mm}$ to $0.5 \mathrm{~mm}$. 


$$
R=\frac{4 \pi A}{P^{2}}
$$

$$
S=\frac{4 A}{\pi(\text { major axis })^{2}}
$$

$$
A R=\frac{\text { MinFeret }}{\text { MaxFeret }}
$$

\section{Morphology of original sand}

Two hundred grains of G500 sand were randomly selected for morphology analysis. The mean MinFeret was $0.645 \pm 0.049 \mathrm{~mm}$. The mean value of MinFeret is a slightly larger than the finest sieve size that the G500 sand passed through, which is $0.6 \mathrm{~mm}$. This is in good agreement with results by Altuhafi et al. (2012) since the sieve size that grains can pass through depends on both the intermediate and minimum grain dimensions. The aspect ratio was $0.776 \pm 0.085$, the roundness was $0.848 \pm 0.030$ and the sphericity was $0.783 \pm 0.096$.

Fig. 15 shows the correlation of sphericity and roundness with aspect ratio for G500 sand. Most grains have a roundness of 0.8 to 0.9 and a sphericity between 0.65 and 0.95 . Grains tend to have a higher sphericity and aspect ratio as the roundness increases. Mathematically, the ratio of sphericity and roundness is equal to the square of the actual perimeter over the perimeter of a circle with a diameter equal to the major axis. For most grains, the major axis of the best fit ellipse is close to the maximum Feret diameter. The resulting perimeter of a circle with a diameter equal to the major axis will be larger than the grain perimeter. However, some sand grains with a high aspect ratio $(>0.9)$ and concave surfaces will result in a higher sphericity compared to the roundness.

The morphology analysis was repeated on 200 randomly sampled grains of G600 sand and the results are shown in shown in Fig. 16. The MinFeret was $0.757 \mathrm{~mm} \pm 0.060 \mathrm{~mm}$. Again, 
341 the mean value of the minimum Feret diameter is slightly larger than the finest sieve size that the

342 G600 sand passed through, which is $0.71 \mathrm{~mm}$. The aspect ratio was $0.792 \pm 0.081$, the roundness

343 was $0.852 \pm 0.029$, and the sphericity was $0.798 \pm 0.092$. Compared to G500 sand, the G600

344 sand grains are closer to circular shapes, and have a slightly lower standard deviation in these 345 three descriptors.

\section{Morphology of sand from crush tests}

After $40 \mathrm{MPa}$ crushing tests were performed, the sand was sieved into different size ranges. The grains retained on each sieve were used for morphology analysis. As shown in Fig. 17, sand grains retained on a $0.5 \mathrm{~mm}$ sieve remain unbroken and have high sphericity and

350 roundness. Sand particles from $0.425 \mathrm{~mm}, 0.355 \mathrm{~mm}$ and $0.3 \mathrm{~mm}$ sieves, typically consist of 351 grains that have been split into two or more fragments. Elongated or tabular particles were more 352 common for the small sand fragments collected on sieves finer than $0.3 \mathrm{~mm}$ in size.

354 collected from the $0.5 \mathrm{~mm}$ sieve had a slightly higher mean roundness $(0.842)$, sphericity $(0.834)$

355 and aspect ratio (0.821) than the original G500 sand prior to the crushing test. Likewise, the 356 grains collected from the $0.6 \mathrm{~mm}$ sieve had a slightly higher mean roundness $(0.853)$, sphericity 357 (0.811) and aspect ratio (0.803) than the original G600 sand. These results indicated that rounder 358 and more spherical grains tend to stay unbroken under compression. For particles collected from 359 the $0.08 \mathrm{~mm}$ sieve, the aspect ratio was 0.570 for G500 sand and 0.615 for G600 sand, which 360 means the maximum Feret diameter was almost two times of the minimum Feret diameter 361 indicating an elongated grain shape. As the sieve size reduces, the mean value of roundness, 362 sphericity and aspect ratio also decrease as seen in Figs. 18 and 19. The mean value of minimum 363 Feret diameter of grains from each sieve has a nearly linear relation with the sieve size. This may 
364 imply that the ratio of the intermediate and minimum grain dimension remains similar for each 365 grain size.

366

367

368

369

370

371

372

373

374 before crushing, which can be expressed as:

375

$$
k_{r}=\frac{e_{2}^{3}\left(1+e_{1}\right)}{e_{1}^{3}\left(1+e_{2}\right)} \times \frac{D_{10,2}^{2}}{D_{10,1}^{2}}
$$

376 where the subscripts 1 and 2 are the value of each parameter before and after crushing 377 respectively.

378 For comparison, a generalised Kozeny-Carman equation considering the particle shape 379 (Carrier 2003) can be used to estimate the influence of grain morphology on permeability. The 380 permeability $\left(k^{\prime}\right)$ is expressed as:

$$
k^{\prime}=\frac{1}{C_{K-C}} \times \frac{e^{3}}{1+e} \times \frac{D_{e f f}^{2}}{S F^{2}}
$$


382 where $C_{K-C}$ is an empirical coefficient, $S F$ is a unitless grain shape factor, and $D_{e f f}$ is the effective

383 diameter that is given as:

384

$$
D_{e f f}=\frac{1}{\sum_{i}\left(f_{i} /\left(D_{l i}^{0404} D_{s i}^{0.595}\right)\right)}
$$

385 where $f_{\mathrm{i}}$ the percentage of particles retained between two sieve sizes, the larger sieve $D_{l i}$ and the 386 smaller sieve $D_{\text {si }}$.

Likewise, a permeability reduction $\left(k_{\mathrm{r}}^{\prime}\right)$ can be expressed as:

where the subscripts 1 and 2 are the value of each parameter before and after crushing 390 respectively.

The void ratio can be interpreted from the sand pack height that was measured during the crush tests. The decrease in the void ratio with compressive stress is shown in Fig. 12 for two

393 typical tests. The void ratios for the G500 sand and G600 sand packs decrease in a similar

394 manner. The higher the compressive stress, the more significant the void ratio decrease. The

395 values of $D_{10}$ and $D_{\text {eff }}$ for each stress interval can be obtained from the grain size distributions 396 obtained by sieve analysis.

At $10 \mathrm{MPa}$ increments in the compressive stress, the values of the shape factor $S F$ were 398 estimated using the suggestion by Fair and Hatch (1933) for different grain shapes. The value of $399 S F$ is 6.1 for the original sand $(0 \mathrm{MPa})$ as grain shapes are nearly round, 6.4 for sand loaded to 10 400 and $20 \mathrm{MPa}$ because a small portion of grains are abraded and split, 7.4 for sand loaded to $40130 \mathrm{MPa}$ because a significant portion of the grains are split, and 7.7 for $40 \mathrm{MPa}$ because many 402 grains are split and fragments are further crushed into angular shapes. 
Using the empirical equations and the data in Table 2, the calculated permeability

404 reduction for each stress level is shown in Fig. 20. The values given by Equations 5 and 8 are

405 close to each other although the generalised Kozeny-Carman equation (Equation 8) tends to give

406 slightly lower values. As the stress increases from 0 to $40 \mathrm{MPa}$, the permeability reduces by up

407 to one order of magnitude. The permeability reduction at stress levels less than $20 \mathrm{MPa}$ is mainly

408 caused by a decrease in void ratio due to grain position realignment due to compaction. The

409 permeability reduction at compression stresses larger than roughly 20 to $30 \mathrm{MPa}$ is caused by

410 decreases in both void ratio and grain diameter as well as changes in the grain shape. Ignoring

411 the grain size, round grains are 1.6 times, $\left(S F_{\text {round }} / S F_{\text {angular }}\right)^{2}=(7.7 / 6.1)^{2}$, more permeable than

412 angular grains, which matches a numerical study using finite element flow simulation through

413 internal pore structures (Garcia et al. 2009). Although the permeability reduction factor for a

414 G500 sand pack is similar to G600 sand at the same stress, G600 sand is 1.4 times more

415 permeable than G500 sand under 0 to $20 \mathrm{MPa}$ compressive stress and 1.3 times more permeable

416 under $40 \mathrm{MPa}$ compressive stress. So while the G600 sand experiences more crushing and fines

417 generation than the G500 sand, the larger initial grain size more than compensates for the

418 presence of the fines in terms of the resulting permeability through the sand pack.

419 Permeability tests by Coulter et al. (1972) found that 5\% fines can cause more than a

$42050 \%$ reduction in proppant pack permeability for mesh 20/40 sand under a compressive stress of

$42124.1 \mathrm{MPa}$. The tests in this paper give a similar result. As shown in Fig. 20, the permeability

422 reduces by about 50\% for both G500 and G600 sand tested under $20 \mathrm{MPa}$ compression. At this

423 stress, $3.5 \%$ and $5 \%$ of the sand grains are crushed respectively, while the sand pack height

424 decreases by 6 to $7 \%$ due to compression as seen from Figs. 7 and 9. The resulting sand pack 
425 conductivity in a hydraulic fracture (sand pack permeability $\times$ sand pack height) is estimated to 426 reduce by about $50 \%$.

\section{Conclusions}

428 This paper examines the crushing characteristics and morphological changes of Jordan

429 Formation sand subjected to varying levels of stress in one-dimensional constrained compression

430 tests. When the effective stresses applied to a sand pack exceed roughly $10 \mathrm{MPa}$ grain crushing

431 initiates and when stresses exceed roughly $30 \mathrm{MPa}$ a significant portion of the quartz grains are

432 crushed. Acoustic emissions caused by grain breaking were directly associated with drops in the

433 compressive stress. With further increase in compressive stress, a zigzag stress-strain response is

434 observed as sand grains break and the sand becomes more compacted. The overall sand pack

435 stress-strain response becomes softer as grains are crushed, especially at stress levels above 436 roughly $30 \mathrm{MPa}$. Since G600 sand experiences more grain crushing than G500 sand it also has a

437 softer stress-strain response than G500 sand at the higher stress levels.

438 The sand grain shape or morphology was characterized by measurements of particle 439 roundness, sphericity, and aspect ratio. Most sand grains from the original Jordan Formation 440 sand have a roundness of 0.8 to 0.9 and a sphericity of 0.65 to 0.95 . The sand grains are 441 generally close to spherical in shape, which is desirable for frac sands. Sand grains analysed after

442 being compressed to $40 \mathrm{MPa}$ show that the uncrushed grains have a higher mean value of 443 roundness and sphericity than values before the crushing test. This suggests that more spherical 444 grains have a higher crushing resistance. Crushed sand collected from finer sieve sizes have 445 mean values of roundness, sphericity and aspect ratio that decrease as the particle becomes 446 smaller. The shape of the particles shifts from nearly spherical grains to diametrically split grains 447 and then to small, elongated and angular fragments for the smaller particle sizes. 
The Kozeny-Carman empirical equations were used to estimate the permeability through

449 a sand pack as a function of the measured particle size, particle shape, and void ratio. The results

450 show that the permeability for sand under $20 \mathrm{MPa}$ compression reduces by more than $40 \%$

451 compared to initial conditions. This is mainly caused by a decrease in void ratio due to

452 compaction. The permeability reduces by over $80 \%$ at a $40 \mathrm{MPa}$ stress, which is jointly caused

453 by void ratio decrease and sand crushing. It is important to note that the permeability reduction

454 that occurs as the sand is crushed is associated with three factors: reduction in void ratio,

455 reduction in particle size, and a shift away from spherical particle shapes.

456 G600 sand is predicted to be 1.3 to 1.4 times more permeable than G500 sand under 457 compressive stresses of 10 to $40 \mathrm{MPa}$ because the average grain size of the sand pack is larger 458 despite a tendency for G600 sand to crush more easily.

459 This paper demonstrates that frac sand selection based only on sand crushing percentage 460 is not sufficient to achieve a higher permeability. Instead, it is recommended that the influence of 461 grain size reduction, changes in particle shape, and reduction in void ratio be evaluated to better 462 understand the sand pack permeability in a hydraulic fracture at depth. For this purpose, a 463 methodology for conducting a more comprehensive assessment of frac sand permeability using 464 easily obtained data from standard crush tests is presented. This methodology does not rely on 465 conducting permeability tests in the laboratory. Instead, the geometric characteristics of the 466 crushed sand are measured and used to predict the permeability using widely accepted empirical 467 equations. 


\section{Acknowledgments}

This work was support by grants from Mitacs and the British Columbia Oil and Gas

Commission. The financial support from a university fellowship and the China Scholarship Council to the first author is also gratefully acknowledged.

\section{References}

Altuhafi, F., O’Sullivan, C., and Cavarretta, I. 2012. Analysis of an image-based method to quantify the size and shape of sand particles. Journal of Geotechnical and Geoenvironmental Engineering, 139(8): 1290-1307.

ASTM D6913 2009. Standard test methods for particle-size distribution gradation of soils using sieve analysis, ASTM D6913 - 042009e1.

Benson, M.E., and Wilson, A.B. 2015. Frac sand in the United States - A geological and industry overview: U.S. Geological Survey Open-File Report 2015-1107, 78 p., http://dx.doi.org/10.3133/ofr20151107 [cited 20 November 2015].

Blott, S.J., and Pye, K. 2008. Particle shape: a review and new methods of characterization and classification. Sedimentology, 55(1): 31-63.

Brown, B. 2012. Hydrofrac sand in Wisconsin. Wisconsin Geological and Natural History Survey. Available from http://monroe.uwex.edu/files/2012/02/Frac_sand_in_Wisconsin1.pdf [cited 20 November 2015].

Carrier III, W.D. 2003. Goodbye, Hazen; Hello, Kozeny-Carman. Journal of Geotechnical and Geoenvironmental Engineering, 129(11): 1054-1056.

Chapuis, R.P. 2004. Predicting the saturated hydraulic conductivity of sand and gravel using effective diameter and void ratio. Canadian Geotechnical Journal, 41(5): 787-795. 
Cheng, Y.P., Bolton, M. D., and Nakata, Y. 2004. Crushing and plastic deformation of soils simulated using DEM. Géotechnique, 54(2): 131-141.

Cho, G.C., Dodds, J., and Santamarina, J.C. 2006. Particle shape effects on packing density, stiffness, and strength: natural and crushed sands. Journal of Geotechnical and Geoenvironmental Engineering, 132(5): 591-602.

Chuhan, F.A., Kjeldstad, A., Bjørlykke, K., and Høeg, K. 2002. Porosity loss in sand by grain crushing - experimental evidence and relevance to reservoir quality. Marine and Petroleum Geology, 19(1): 39-53.

Coop, M.R. and Lee, I.K. 1993. The behaviour of granular soils at high stresses. In Predictive Soil Mechanics: Proceedings of the Wroth Memorial Symposium on predictive soil mechanics, pp. 186-198.

Coop, M.R., Sorensen, K.K., Freitas, T.B., and Georgoutsos, G. 2004. Particle breakage during shearing of a carbonate sand. Géotechnique, 54(3): 157-163.

Coulter, G.R., and Wells, R.D. 1972. The advantages of high proppant concentration in fracture stimulation. Journal of Petroleum Technology, 24(6): 643-650.

Fair, G.M., and Hatch, L.P. 1933. Fundamental factors governing the stream-line flow of water through sand. Journal of American Water Works Association, 25(11): 1551-1565.

Garcia, X., Akanji, L.T., Blunt, M.J., Matthai, S.K., and Latham, J.P. 2009. Numerical study of the effects of particle shape and polydispersity on permeability. Physical Review E, 80(2), 021304.

Gaurav, A., Dao, E.K., and Mohanty, K.K. 2012. Evaluation of ultra-light-weight proppants for shale fracturing. Journal of Petroleum Science and Engineering, 92: 82-88. 
Ghafghazi, M., Shuttle, D.A., and DeJong, J.T. 2014. Particle breakage and the critical state of sand. Soils and Foundations, 54(3): 451-461.

Göktepe, A.B., and Sezer, A. 2010. Effect of particle shape on density and permeability of sands. Proceedings of the ICE-Geotechnical Engineering, 163(6): 307-320.

Guo, P.J., and Stolle, D.F.E. 2006. Fabric and particle shape influence on $\mathrm{k}_{0}$ of granular materials. Soils and Foundations, 46(5): 639-652.

Hagerty, M., Hite, D., Ullrich, C., and Hagerty, D. 1993. One-dimensional high-pressure compression of granular media. Journal of Geotechnical Engineering, 119(1): 1-18.

Hardin, B.O. 1985. Crushing of soil particles. Journal of Geotechnical Engineering, 111(10): 1177-1192.

ISO 13503-2:2006. Petroleum and natural gas industries - Completion fluids and materials - Part 2: Measurement of properties of proppants used in hydraulic fracturing and gravel-packing operations.

Krumbein, W.C., and Sloss, L.L. 1963. Stratigraphy and sedimentation, 2nd Ed., Freeman, San Francisco.

Kurz, B.A., Schmidt, D.D., and Cortese, P.E. 2013. Investigation of improved conductivity and proppant applications in the Bakken formation. In SPE Hydraulic Fracturing Technology Conference. Society of Petroleum Engineers.

Lacy, L.L., Rickards, A.R., and Ali, S.A. 1997. Embedment and fracture conductivity in soft formations associated with HEC, borate and water-based fracture designs. In SPE Annual Technical Conference and Exhibition. Society of Petroleum Engineers.

Lade, P.V., Yamamuro, J.A., and Bopp, P.A. 1996. Significance of particle crushing in granular materials. Journal of Geotechnical Engineering, 122(4): 309-316. 
Latham, J.P., Munjiza, A., and Lu, Y. 2002. On the prediction of void porosity and packing of rock particulates. Powder Technology, 125(1): 10-27.

Luzzani, L., and Coop, M.R. 2002. On the relationship between particle breakage and the critical state of sands. Soils and Foundations 42(2): 71-82.

Mudrey, M.G. LaBerge, Jr., Myers, P.E., and Cordua, W.S. 1987. Bedrock geology of Wisconsin: Northwest sheet. University of Wisconsin-Extension, Geological and Natural History Survey.

Nakata, Y., Hyde, A., Hyodo, M., and Murata, H. 1999. A probabilistic approach to sand particle crushing in the triaxial test. Géotechnique, 49(5): 567-583.

Nakata, Y., Kato, Y., Hyodo, M., Hyde, A., and Murata H. 2001. One-dimensional compression behaviour of uniformly graded sand related to single particle crushing strength. Soils and Foundations, 41(2): 39-51.

Odom, I.E. 1975. Feldspar-grain size relations in Cambrian arenites, Upper Mississippi Valley. Journal of Sedimentary Petrology, 45(3): 636-650.

Odom, I.E. 1978. Mineralogy of Cambrian sandstones, upper Mississippi Valley: Wisconsin Geological and Natural History Survey Field Trip Guidebook 3, p. 23-45.

Ostrom, M.E., 1971, Preliminary Report on Results of Physical and Chemical Tests of Wisconsin Silica Sandstones: Wisconsin Geological and Natural History Survey Information Circular 18, 61p.

Palisch, T.T., Duenckel, R. J., Chapman, M. A., Woolfolk, S., and Vincent, M. C. 2009. How to use and misuse proppant crush tests - exposing the top 10 myths. In SPE Hydraulic Fracturing Technology Conference. Society of Petroleum Engineers. 
Parab, N.D., Claus, B., Hudspeth, M.C., Black, J.T., Mondal, A., Sun, J., Fezzaa, K., Xiao, X., Luo, S.N., and Chen, W. 2014. Experimental assessment of fracture of individual sand particles at different loading rates. International Journal of Impact Engineering, 68: 8-14.

Romanson, R., Riviere, N., Taylor, B., McIntosh, G., Wilson, M., Loran, C., and Cockbill, J. 2010. Montney fracturing-fluid considerations: case history. In Canadian Unconventional Resources and International Petroleum Conference. Society of Petroleum Engineers.

Runkel, A.C. 1994a. Deposition of the uppermost Cambrian Croixan Jordan Sandstone, and the nature of the Cambrian-Ordovician boundary in the upper Mississippi Valley: Geological Society of America Bulletin 106: 492-506.

Runkel, A.C. 1994b. Revisions to the stratigraphic nomenclature of the Jordan Sandstone, upper Mississippi Valley region: Shorter contributions to the Minnesota Geological Survey Report of Investigations 43, p. 60-71.

Runkel, A.C. 2000. Sedimentology of the Upper Cambrian Jordan Sandstone-A classic cratonic sheet sandstone deposited during regression in a "typical" marine setting, Guidebook for 30th Annual Field Conference, Great Lakes Section for the Society for Sedimentary Geology, p. 43-46.

Runkel, A.C., Syverson, K., Steenberg, J., Bendernagel, M., Bauer, A., Kent, A., Thompson, M., Stauffer, T., and Brown, B., eds. 2012. Field guidebook on the silica sand resources of western Wisconsin, Conference on the silica sand resources of Minnesota and Wisconsin, Precambrian Research Center Guidebook 12-01: Brooklyn Park, Minnesota, 45 p.

Schneider, C.A., Rasband, W. S., and Eliceiri, K. W. 2012. NIH Image to ImageJ: 25 years of image analysis. Nature Methods, 9: 671-675. 
Song, L., and Hareland, G. 2012. Minimum horizontal stress profile from logging data for Montney Formation of North East British Columbia. In SPE Canadian Unconventional Resources Conference, Society of Petroleum Engineers.

Terzaghi, K. and Peck, R.B. 1948. Soil mechanics in engineering practice. John Wiley, New York.

Tsomokos, A., and Georgiannou, V.N. 2010. Effect of grain shape and angularity on the undrained response of fine sands. Canadian Geotechnical Journal, 47(5): 539-551.

Ueda, T., Matsushima, T., and Yamada, Y. 2013. DEM simulation on the one-dimensional compression behavior of various shaped crushable granular materials. Granular Matter, 15(5): $675-684$.

Vilhar, G., Jovičić, V., \& Coop, M.R. 2013. The role of particle breakage in the mechanics of a non-plastic silty sand. Soils and Foundations, 53(1), 91-104.

Winchell, N.H. 1874. The geology of the Minnesota Valley, part e The Jordan Sandstone: Geological and Natural History Survey of Minnesota, Second Annual Report, p. 147-152.

Wisconsin Department of Natural Resources. 2012. Silica Sand Mining in Wisconsin. Available from http://dnr.wi.gov/topic/mines/documents/silicasandminingfinal.pdf [cited 20 November 2015].

Wisconsin Geological and Natural History Survey. 2014. Frac sand in Wisconsin. Available from http://wgnhs.uwex.edu/pubs/fs05/ [cited 20 November 2015].

Yimsiri, S., and Soga, K. 1999. Effect of surface roughness on small-strain modulus: micromechanics view. Pre-failure Deformation Characteristics of Geomaterials, 1: 597-602.

Zhang, X., and Baudet, B.A. 2013. Particle breakage in gap-graded soil. Géotechnique Letters, 3: $72-77$. 
Zhao, X., Cai, M., Wang, J., and Ma, L. 2013. Damage stress and acoustic emission characteristics of the Beishan granite. International Journal of Rock Mechanics and Mining Sciences, 64, 258-269. 
Table 1. Grain size distribution of mesh 20/40 sand

\begin{tabular}{ccccccccc}
\hline Sieve size $(\mathrm{mm})$ & 1.0 & 0.85 & 0.71 & 0.6 & 0.5 & 0.425 & 0.355 & 0.3 \\
(mesh No.) & $(18)$ & $(20)$ & $(25)$ & $(30)$ & $(35)$ & $(40)$ & $(45)$ & $(50)$ \\
Weight percent retained & 0 & 2.4 & 12.4 & 37.9 & 42.1 & 4.9 & 0.3 & 0 \\
\hline
\end{tabular}

Table 2. Parameters for permeability reduction estimation using empirical equations

\begin{tabular}{c|cccc|cccc}
\hline \multirow{2}{*}{$\begin{array}{c}\text { Stress } \\
(\mathrm{MPa})\end{array}$} & \multicolumn{4}{|c|}{$\mathrm{G} 500$ sand } & \multicolumn{4}{c}{$\mathrm{G} 600$ sand } \\
\hline 0 & 0.658 & 0.60 & 0.539 & 6.1 & 0.655 & 0.71 & 0.643 & 6.1 \\
10 & 0.597 & 0.53 & 0.536 & 6.4 & 0.597 & 0.62 & 0.634 & 6.4 \\
20 & 0.561 & 0.515 & 0.530 & 6.4 & 0.561 & 0.61 & 0.628 & 6.4 \\
30 & 0.521 & 0.50 & 0.508 & 7.4 & 0.517 & 0.575 & 0.593 & 7.4 \\
40 & 0.454 & 0.30 & 0.443 & 7.7 & 0.444 & 0.325 & 0.516 & 7.7 \\
\hline
\end{tabular}




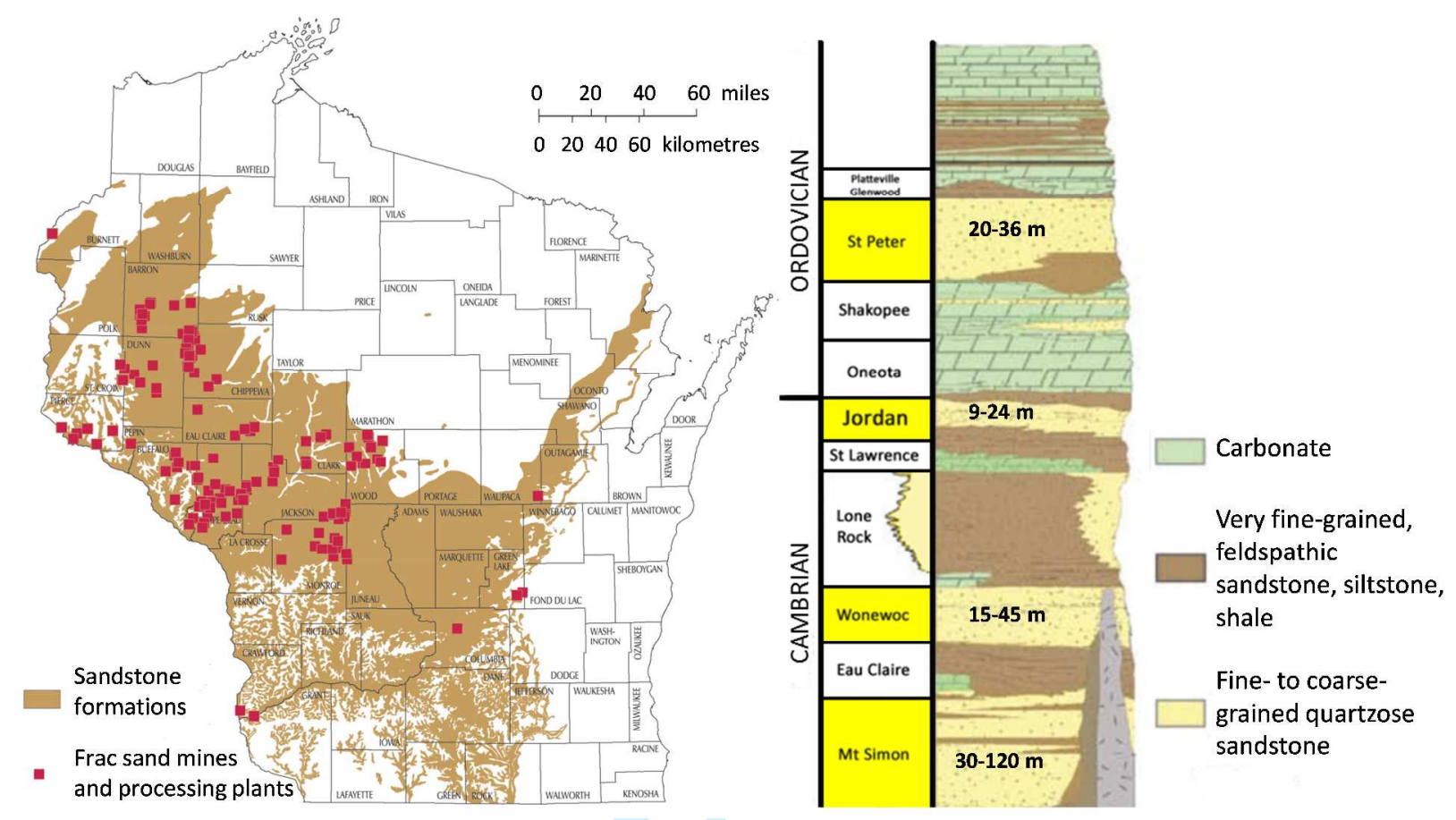

Fig 1. Frac sand mines and sandstone formations in Wisconsin and typical geological section (Modified from Wisconsin Geological and Natural History Survey 2014, and Runkel et al. 2012)

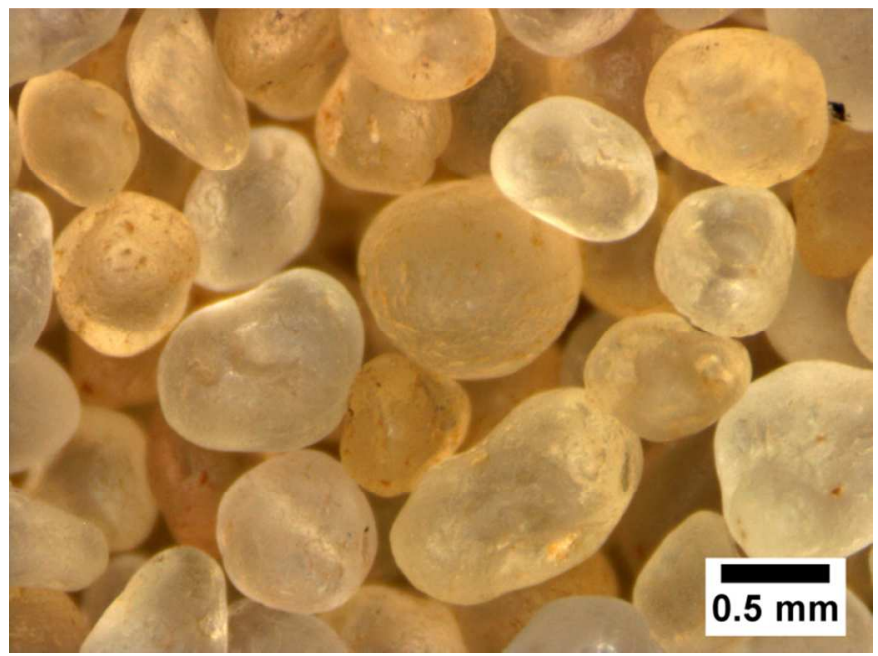

Fig 2. Mesh 20/40 Jordan frac sand 

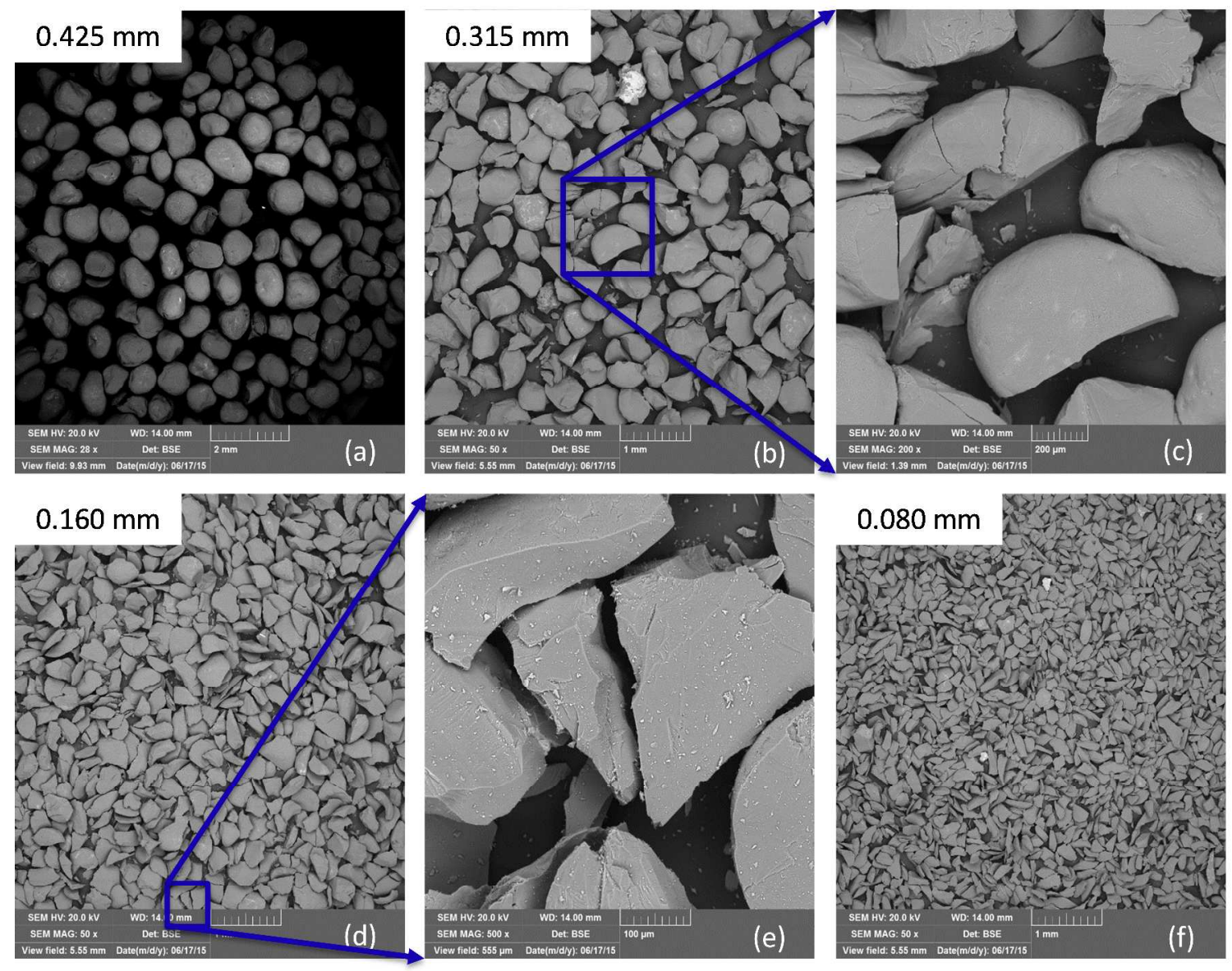

Fig 3. SEM images of sand grains from different sieve sizes

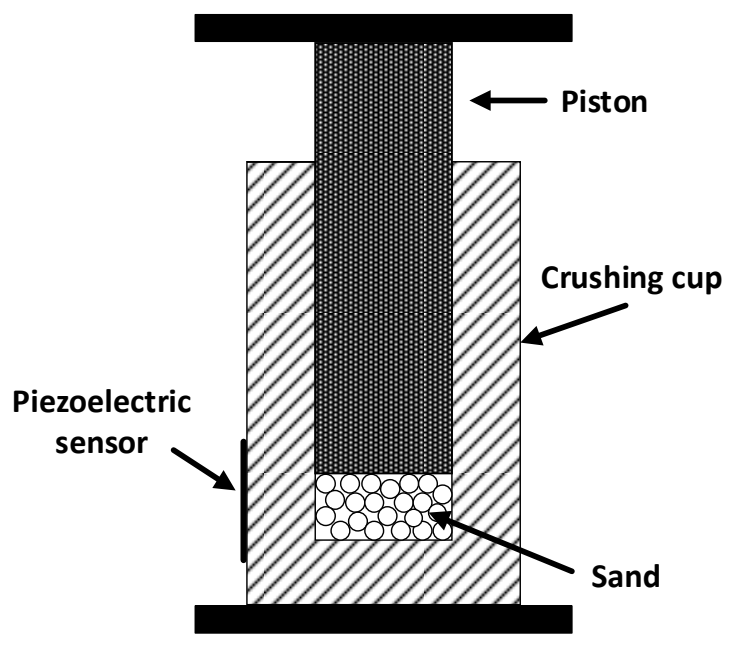

Fig 4. Steel cup and piston used for a one-dimensional compression test 

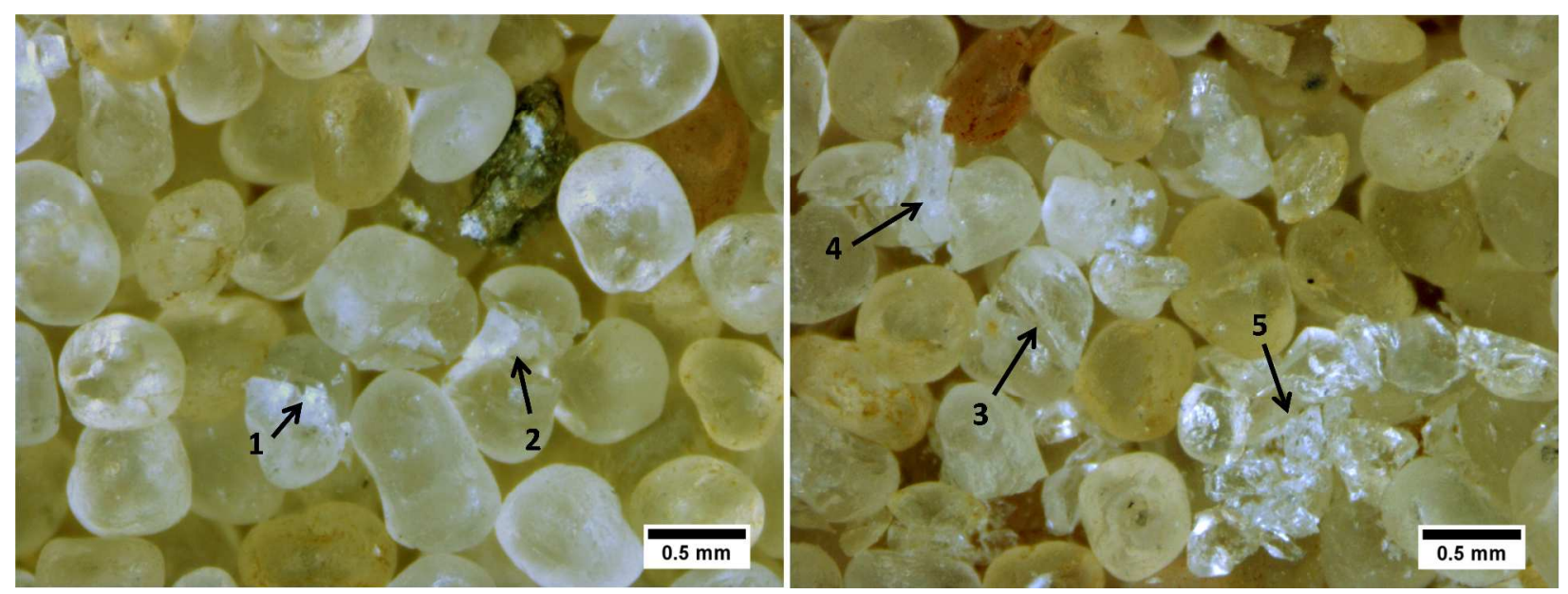

Fig 5. Crushed and intact sand grains after $30 \mathrm{MPa}$ (left) and $40 \mathrm{MPa}$ (right) compression

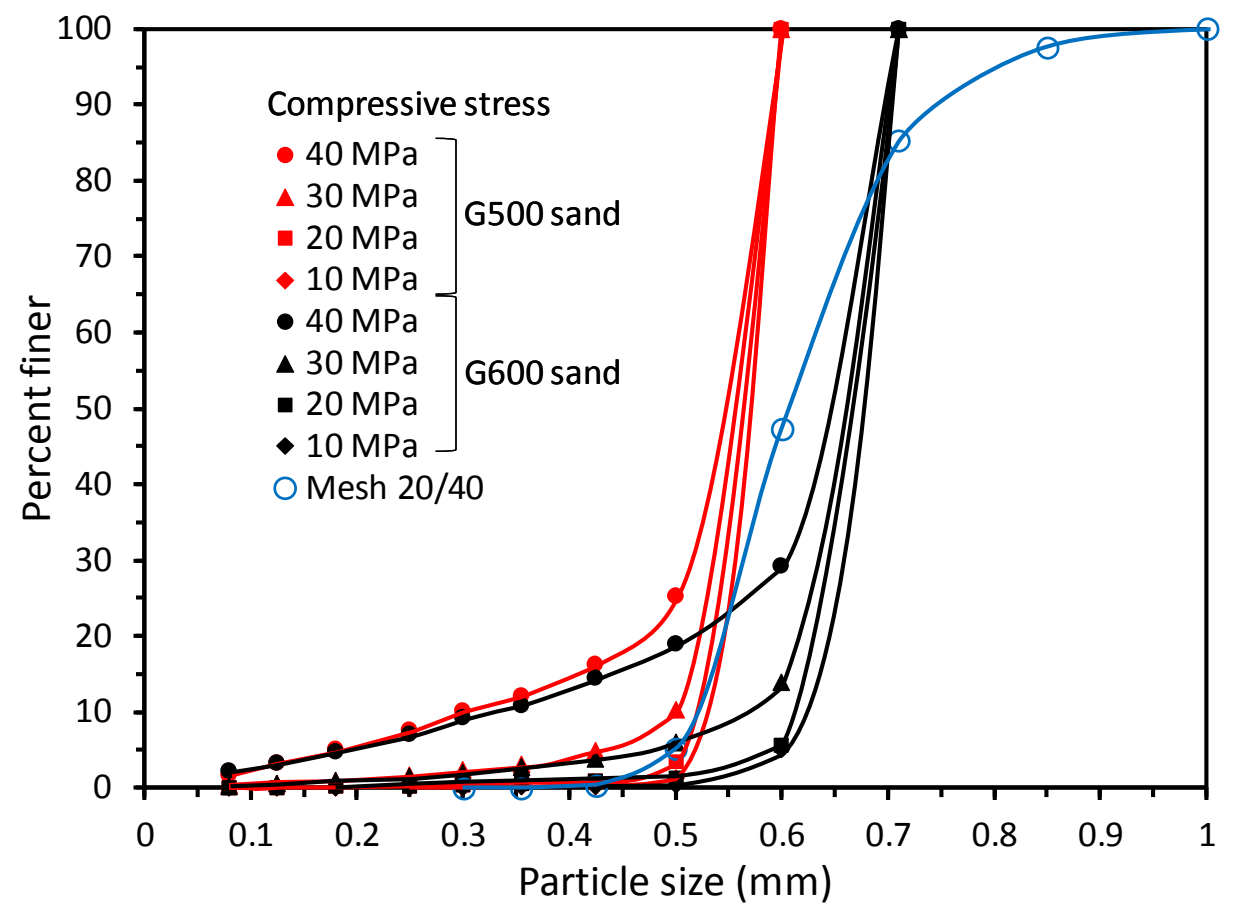

Fig 6. Grain size distributions of G500 and G600 sand under different stress levels 


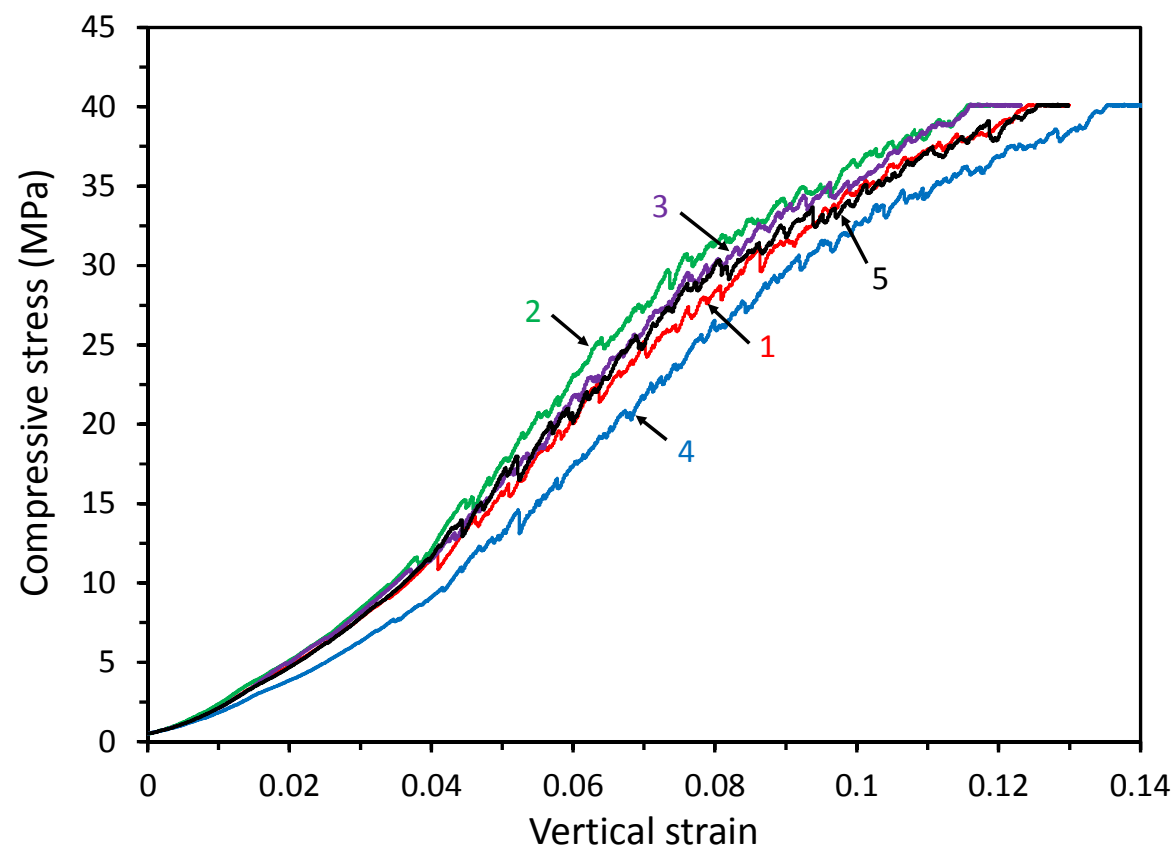

Fig 7. Stress-strain response from five crush tests on G500 sand

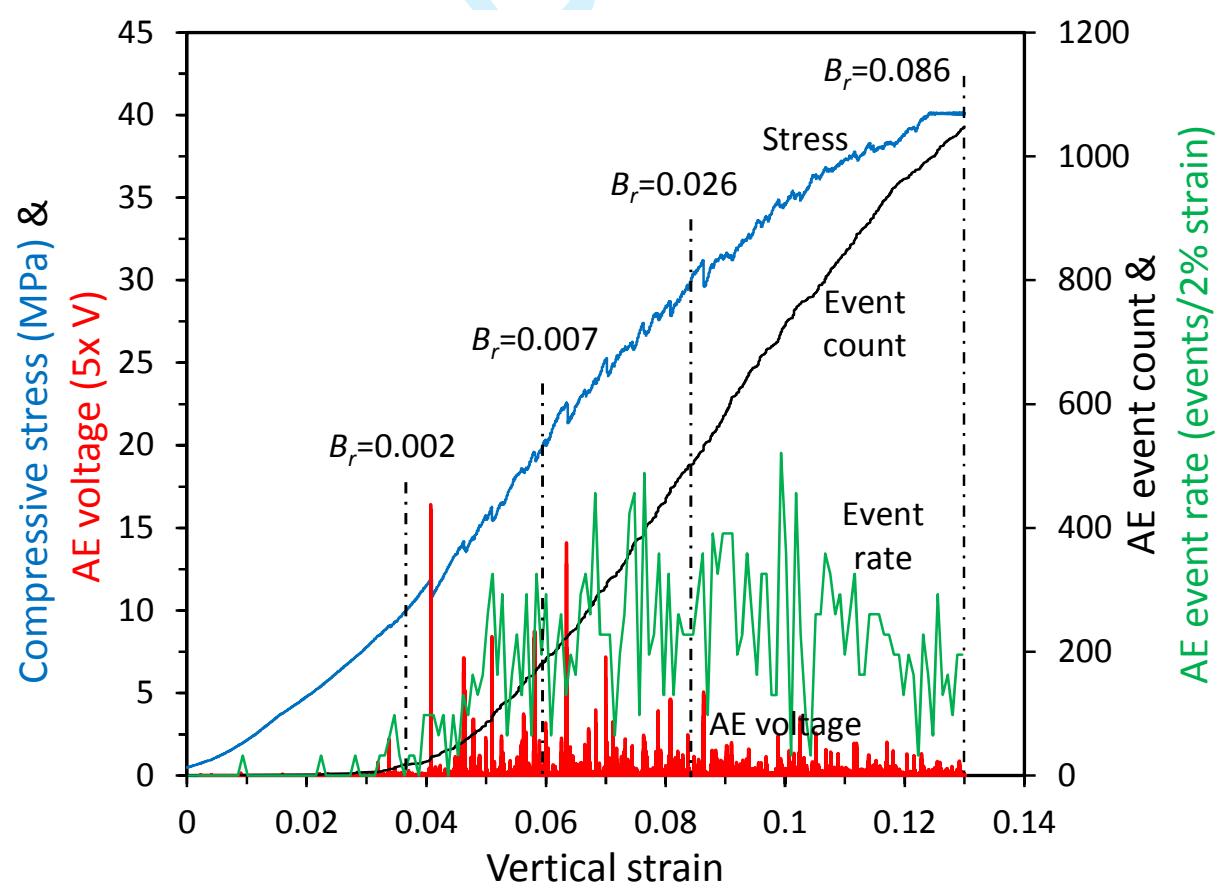

Fig 8. Compressive stress and AE data versus strain for G500 sand (Test 1) 


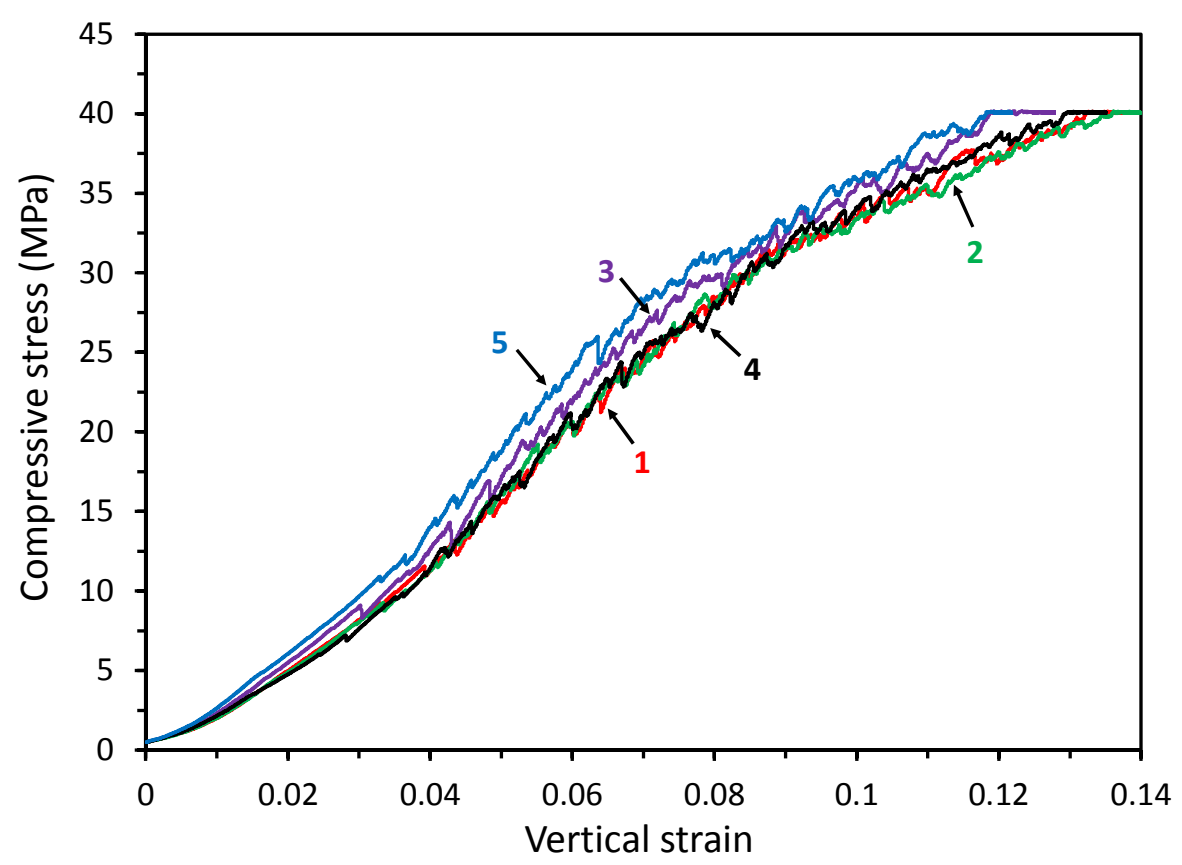

Fig 9. Stress-strain response from five crush tests on G600 sand

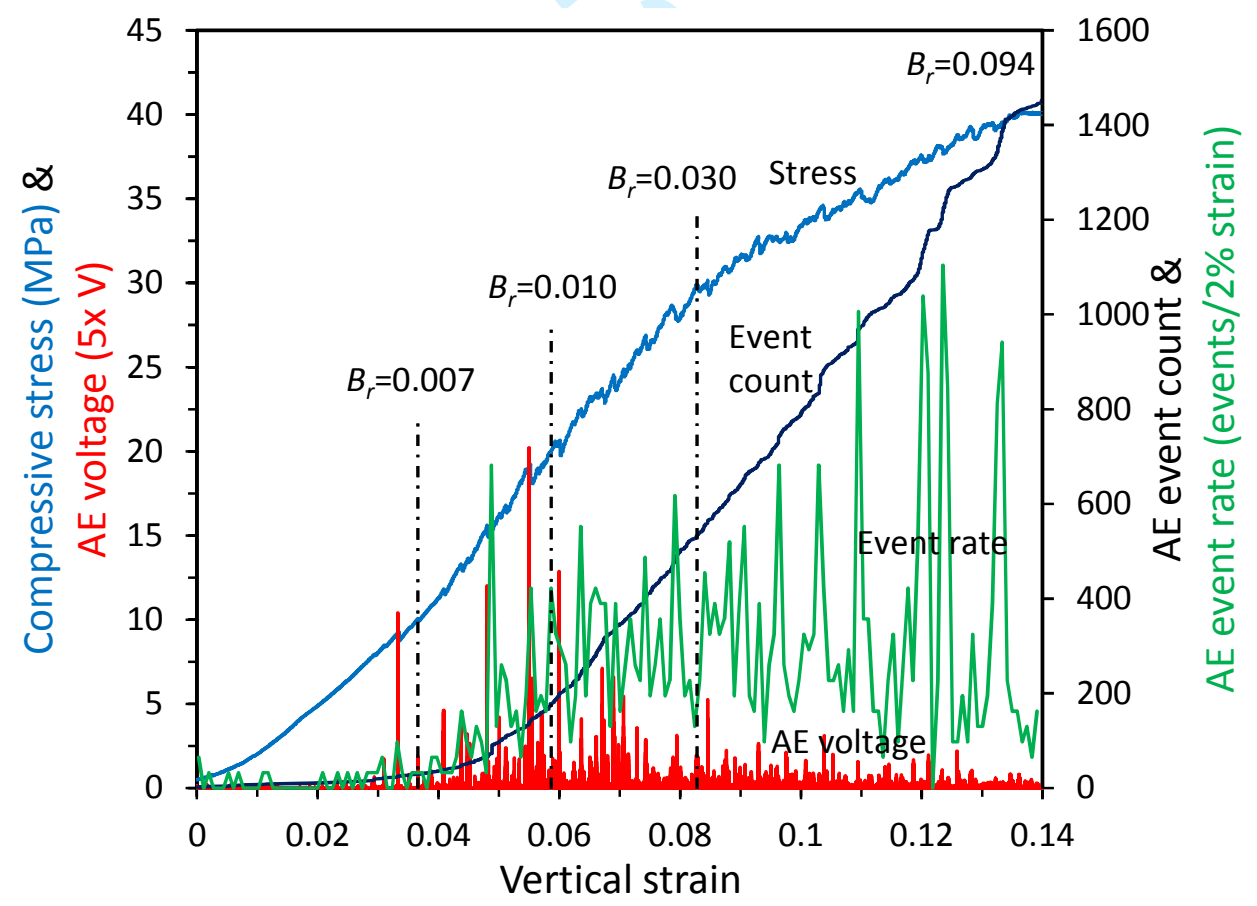

Fig 10. Compressive stress and AE data versus strain for G600 sand (Test 2) 


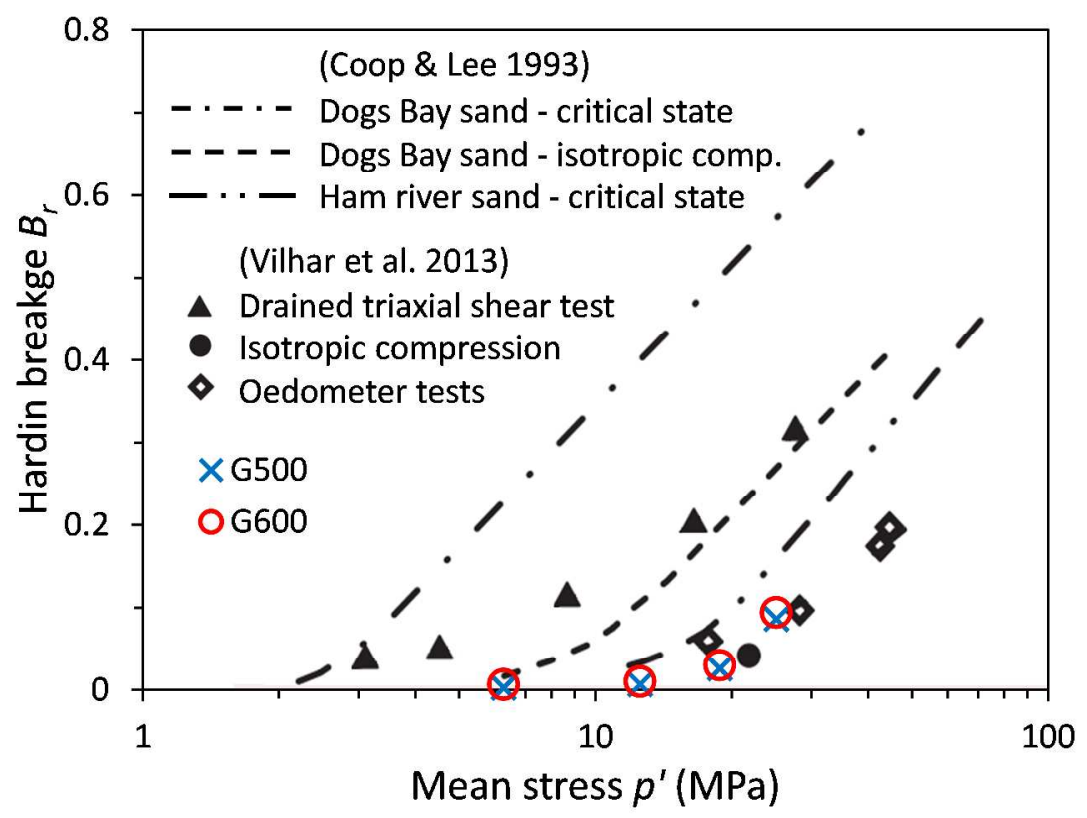

Fig 11. Comparison between particle breakage measured in this study and other test results

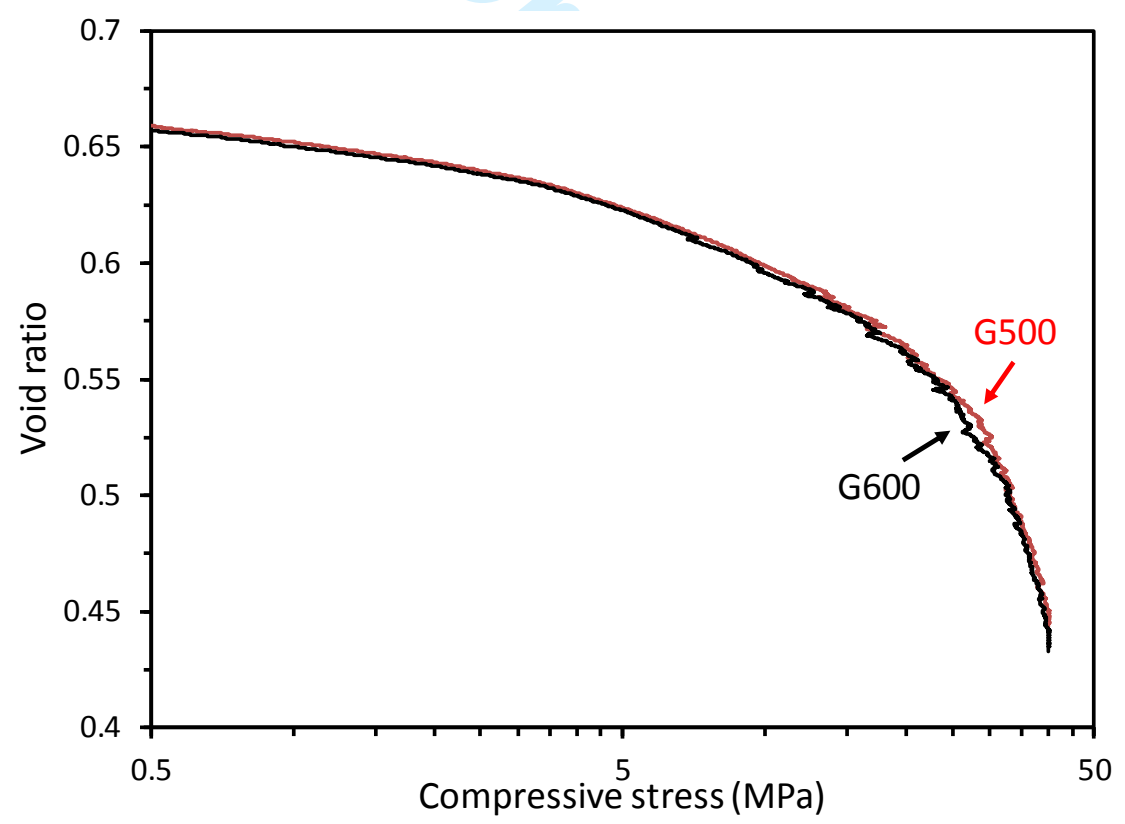

Fig 12. Sand pack void ratio versus compressive stress. 


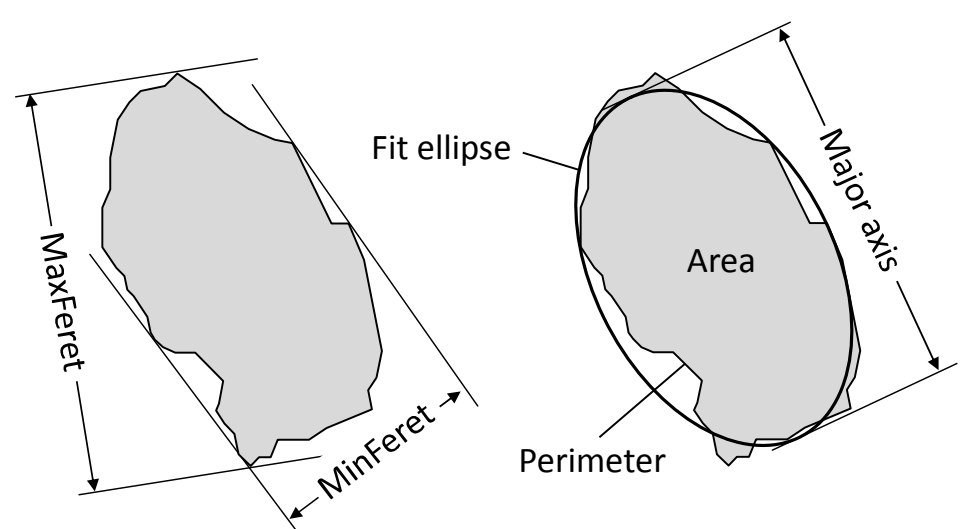

Fig 13. Morphological properties of particle shape

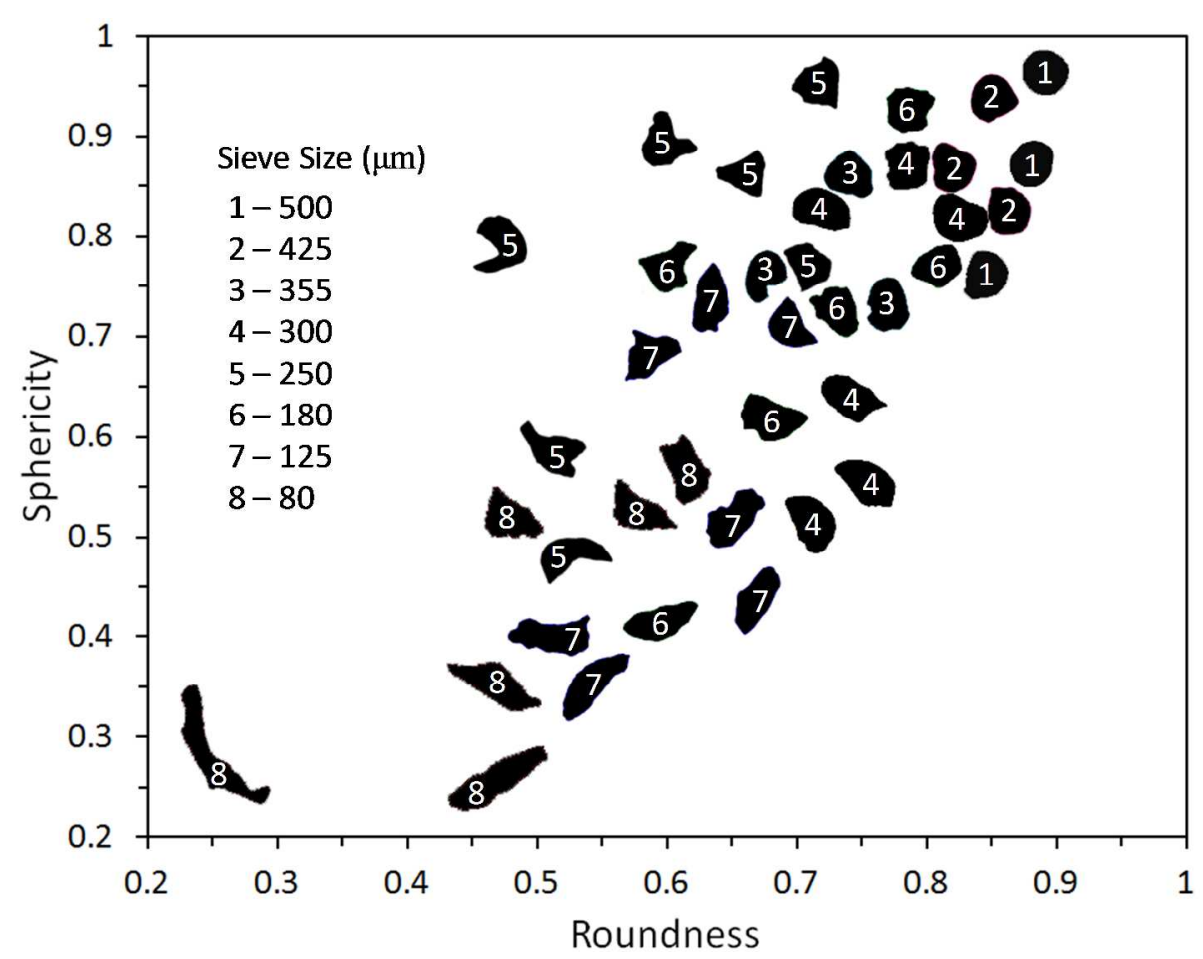

Fig 14. Shape of sand particles $(0.08-0.5 \mathrm{~mm})$ along with their measured roundness and sphericity (each particle outline has been scaled to approximately the same size). 


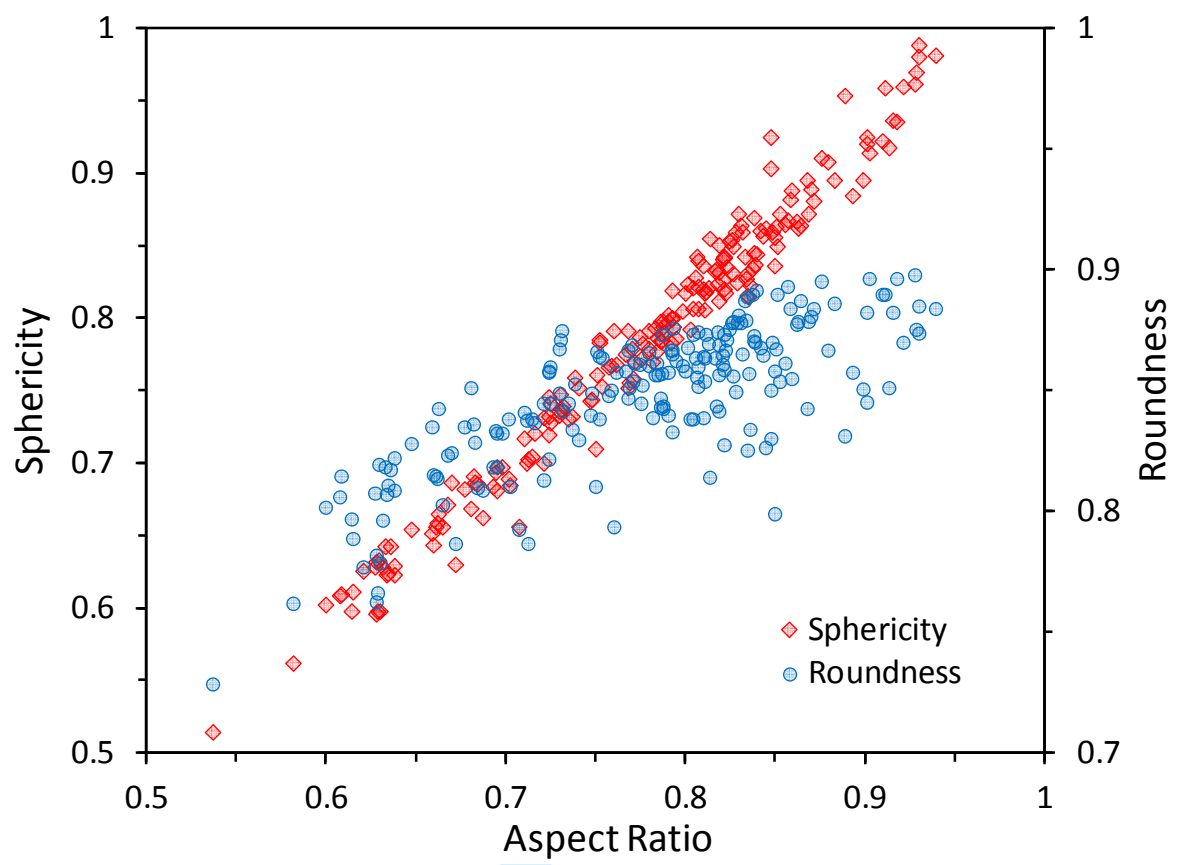

Fig 15. Correlation of sphericity and roundness with aspect ratio for G500 sand

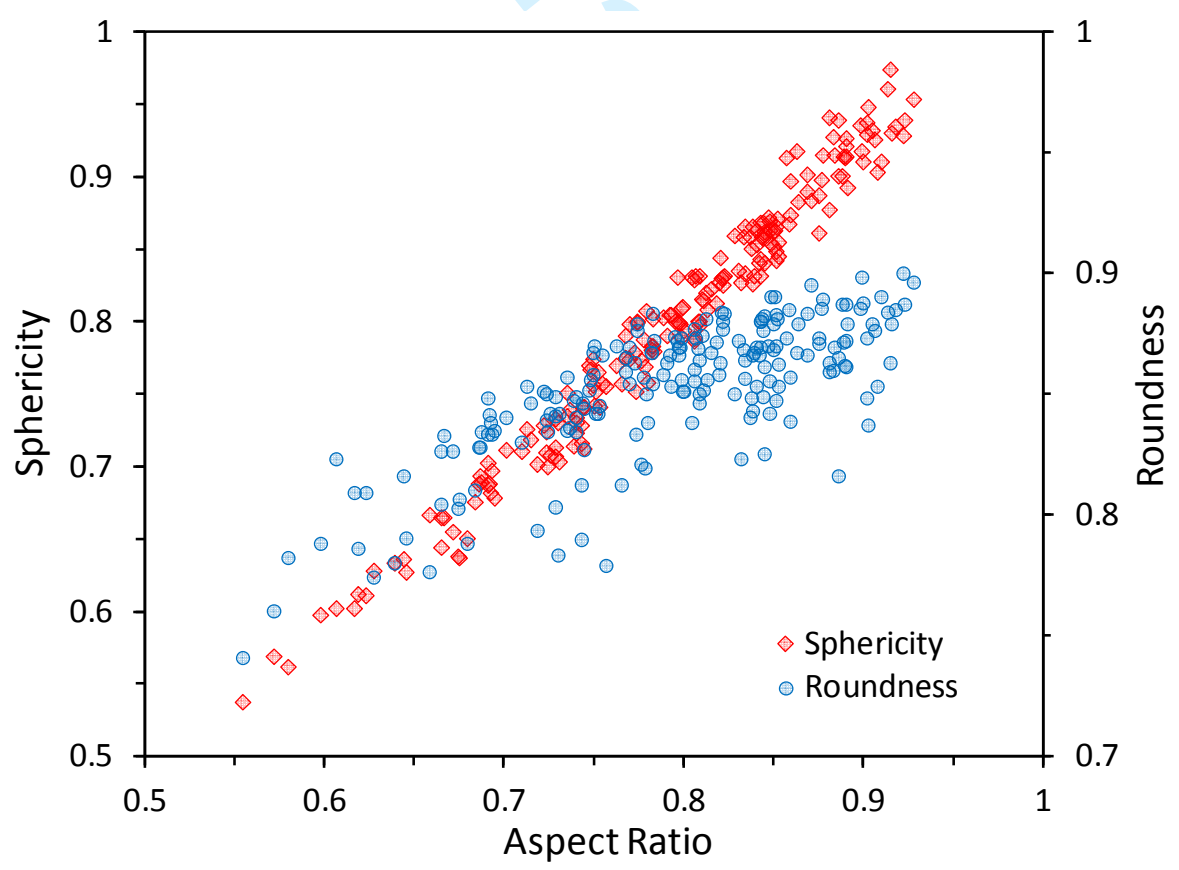

Fig 16. Correlation of sphericity and roundness with aspect ratio for G600 sand 


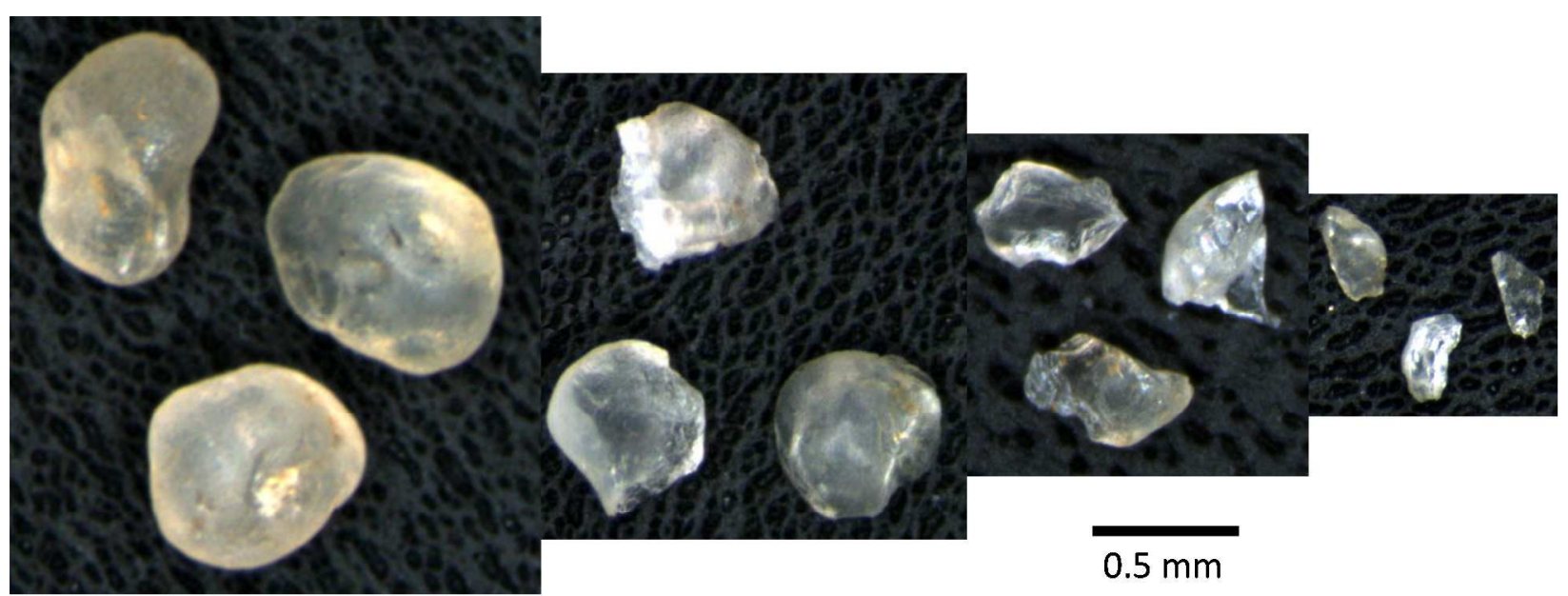

Fig 17. Shape of grains from different sieves (left to right: $0.5,0.355,0.25$, and $0.125 \mathrm{~mm}$ ) after a crushing test on G500 sand.

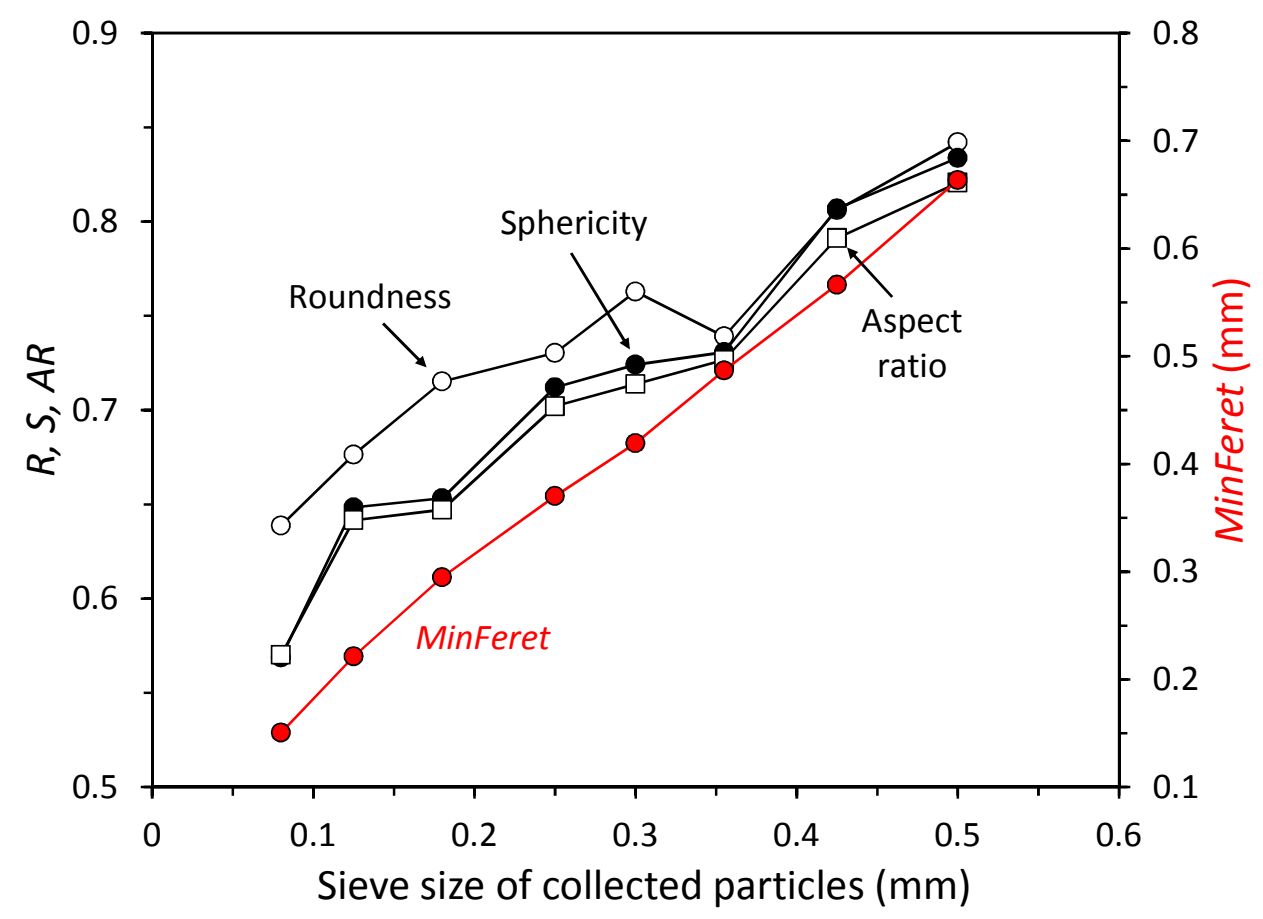

Fig 18. Mean values of geometry descriptors versus sieve size for G500 sand. 


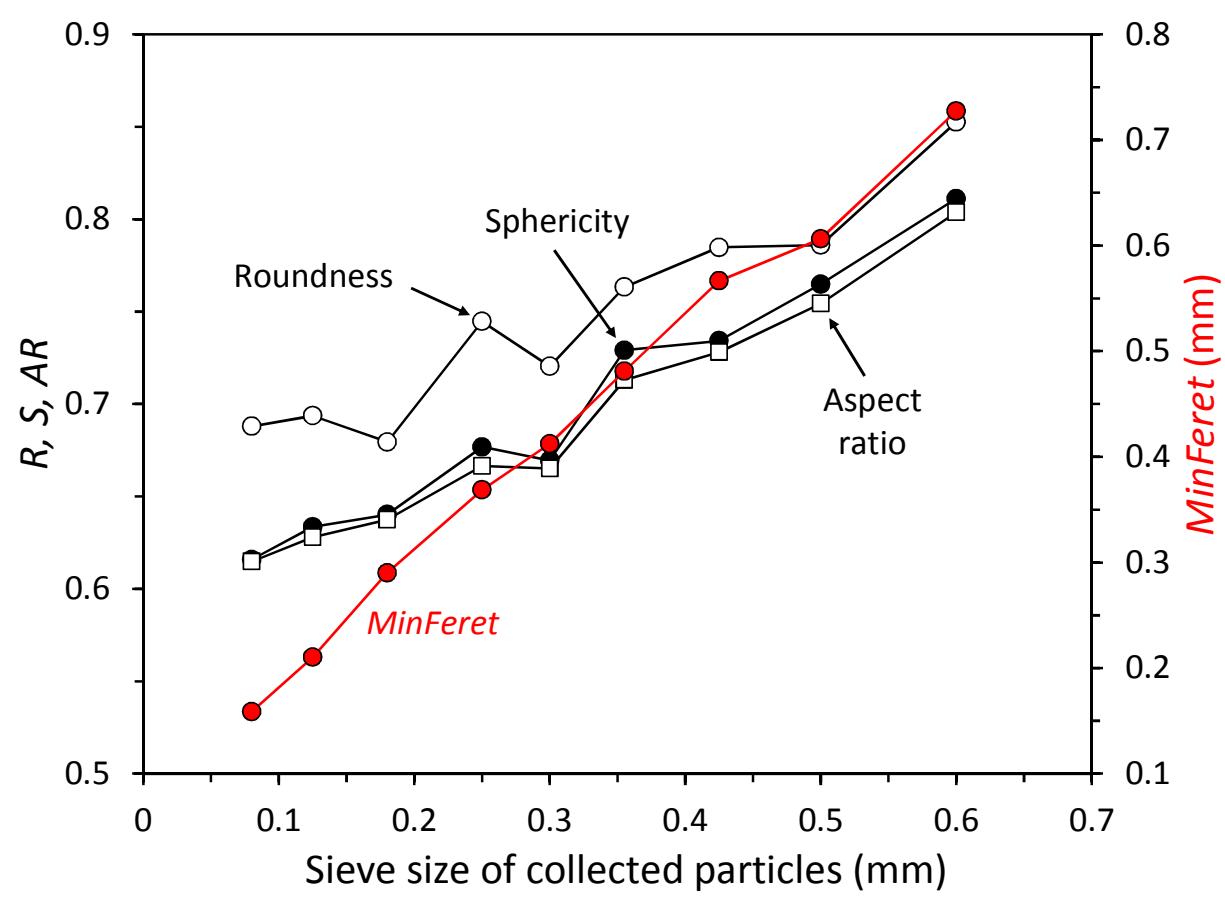

Fig 19. Mean values of geometry descriptors versus sieve size for G600 sand.

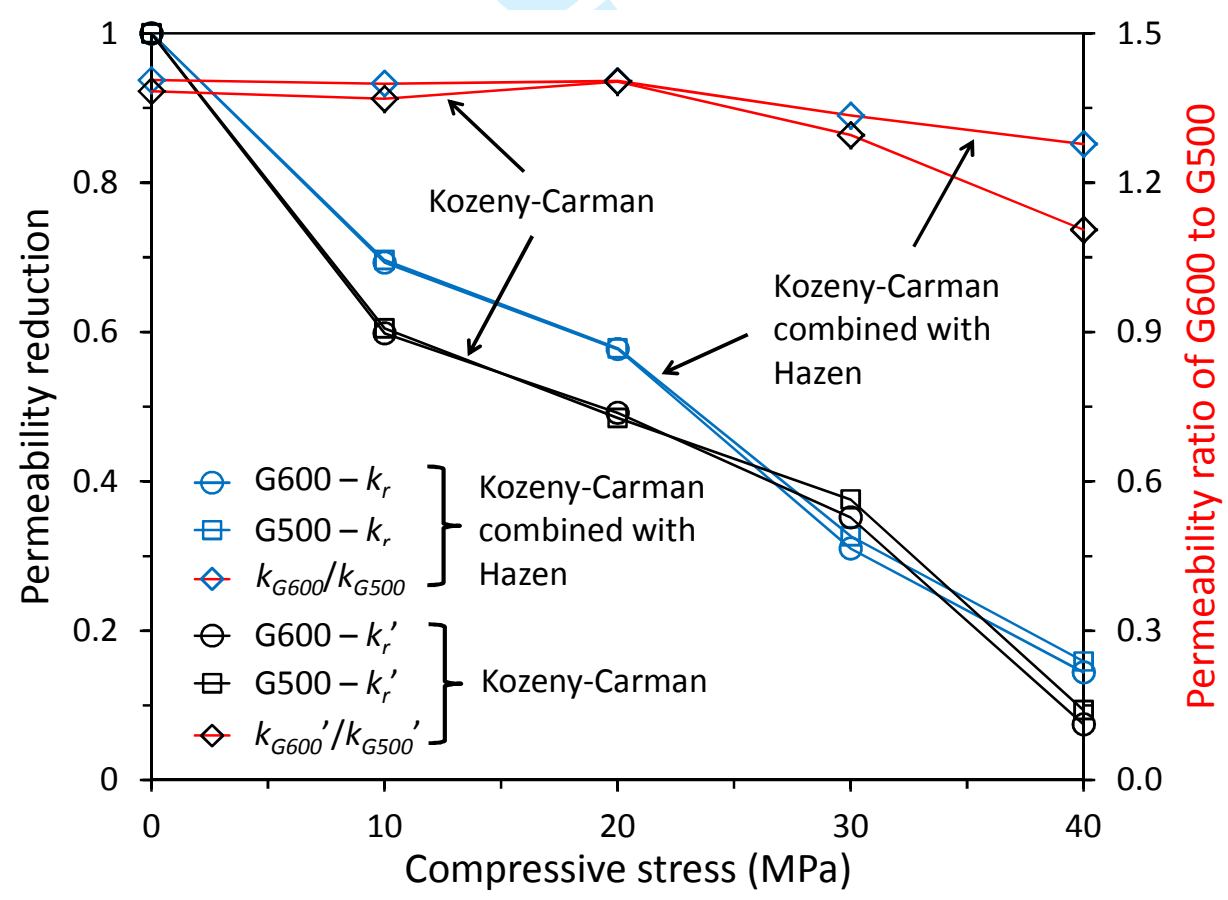

Fig 20. Permeability reduction and permeability ratio of G600 and G500 under different stress 